\title{
THE LIQUIDITY EFFECT AND LONG-RUN NEUTRALITY
}

\author{
Ben S. Bernanke \\ Ilian Mihov
}

\author{
Working Paper 6608 \\ http://www.nber.org/papers/w6608
}

\section{NATIONAL BUREAU OF ECONOMIC RESEARCH \\ 1050 Massachusetts Avenue \\ Cambridge, MA 02138 \\ June 1998}

Bernanke acknowledges the support of the National Science Foundation and Mihov acknowledges the support of the INSEAD Research Fund. Mark Watson and Jordi Gale provided invaluable comments. Any opinions expressed are those of the author and not those of the National Bureau of Economic Research.

(C) 1998 by Ben S. Bernanke and Ilian Mihov. All rights reserved. Short sections of text, not to exceed two paragraphs, may be quoted without explicit permission provided that full credit, including (C) notice, is given to the source. 
The Liquidity Effect and Long-Run Neutrality

Ben S. Bernanke and Ilian Mihov

NBER Working Paper No. 6608

June 1998

JEL \# E5, E52

\section{ABSTRACT}

The propositions that monetary expansion lowers short-term nominal interest rates (the liquidity effect), and that monetary policy does not have long-run real effects (long-run neutrality), are widely accepted, yet to date the empirical evidence for both is mixed. We reconsider both propositions simultaneously in a structural VAR context, using a model of the market for bank reserves due to Bernanke and Mihov (forthcoming). We find little basis for rejecting either the liquidity effect or long-run neutrality. Our results are robust over the space of admissible model parameter values, and to the use of long-run rather than short-run identifying restrictions.

Ben S. Bernanke

Woodrow Wilson School

Princeton University

Princeton, NJ 08544

and NBER

bernanke@wws.princeton.edu
Ilian Mihov

INSEAD

77305 Fontainebleau

FRANCE 


\section{Introduction}

Although many controversies surround the question of how, and to what extent, monetary policy can affect the economy, there are two empirical propositions about the effects of money that are widely accepted among policy-makers and monetary economists generally. The first, the so-called liquidity effect (LE), asserts that in the short run, changes in the money supply $y^{1}$ induce changes in short-term nominal interest rates of the opposite sign. The second proposition, the longrun neutrality of money (LRN), states that changes in the money supply do not have significant effects on real quantities such as output, employment, real interest rates, and real balances in the long run.

Although these two propositions appear to command wide assent (as illustrated, for example, by their prominence in undergraduate macroeconomics textbooks), formal empirical tests of these propositions have yielded surprisingly mixed results. The empirical support for the liquidity effect, for example, has passed through several phases. Early research on the subject generally found that, if money growth is treated as exogenous, increases in the money stock tend to be associated with subsequent declines in interest rates, consistent with the liquidity effect hypothesis (see, e.g., Cagan and Gandolfi, 1969; Gibson, 1968; Cagan, 1972). However, Melvin (1983) and Reichenstein (1987) subsequently concluded that the liquidity effect vanished in the 1970s, i.e., after 1973 or so the pattern of increases in money growth being followed by falling interest rates no longer appeared to hold.

During the 1980s, in the wake of the rational expectations revolution, tests of the liquidity effect began to focus on the relationship between unanticipated changes in the money stock and interest rates. The results were not encouraging for the liquidity effect. For example, Mishkin (1982, 1983) documented that the 
correlation between innovations in money and interest rates is typically positive or zero, not negative. At about the same time, a large literature on money supply announcements (see Cornell, 1983, for a review) found that announcements of higher-than-expected money growth tended to be associated with increases, not decreases, in short-term interest rates, contrary to the conventional prediction.

A more recent wave of research has also found mixed evidence for the liquidity effect. On the positive side, using a band-pass filter to eliminate very high frequency movements in money and interest rates, Cochrane (1989) found evidence for the "return of the liquidity effect" for the 1979-82 period. However, he also found little correlation of money and interest rates during the 1976-79 and 1982-86 periods. Gali (1992) found support for the liquidity effect in a specification identified in part by the assumption of long-run monetary neutrality, and strongin (1995) isolated a statistically significant negative correlation between various bank reserves measures and the federal funds rate. On the other hand, Leeper and Gordon (1992) documented that over a wide range of specifications the response of interest rates to a money growth innovation is positive; and Pagan and Robertson (1995) and Christiano (1995) report a "vanishing" liquidity effect for the period after 1982. Most recently, a number of VAR-based studies have found evidence consistent with the liquidity effect (see Bernanke and Mihov, forthcoming, for a review and discussion), although the validity of the VAR-based approach has also been criticized (Rudebusch, 1997). As the liquidity effect plays a central role in conventional views of the monetary transmission mechanism, and since theoretical monetary models are often evaluated in part on whether they imply the existence of a liquidity effect, the inconsistent support of formal empirical studies for the LE proposition is discouraging to say the least. 
The proposition of long-run monetary neutrality, despite a degree of acceptance by the economics profession which is if anything greater than that for the liquidity effect, has faced similar empirical problems. Many studies, both older and more recent, have found that monetary policy changes may induce surprisingly drawn-out responses in output and other real variables (to cite studies widely separated in time and in methodology, see for example Anderson and Jordan, 1968, and Romer and Romer, 1989 and 1994). Cochrane (1995) notes that the output response to money innovations in a VAR context is "puzzlingly protracted", a finding he uses to motivate his argument that anticipated as well as unanticipated changes in money may affect output. Gordon and Leeper (1994) similarly find that monetary policy shocks affect output over long horizons, accounting for over $30 \%$ of the unforecasted variation in output three years after the policy shock.

Much recent work on LRN has been motivated by the demonstration, due originally to sargent (1971) and Lucas (1972), and extended to the frequency domain by McCallum (1984), that there may be situations in which LRN is untestable, at least in any simple reduced-form framework. The Sargent-Lucas-McCallum examples involve postulated environments in which the money stock is a stationary process, so that the highly persistent changes in money needed to test LRN are never observed in the data; the inadequacy of reduced-form methods in this situation is essentially an application of Lucas's (1976) famous critique. Fisher and seater (1993) and King and Watson (1997) have pointed out that, in fact, money appears to be an integrated process, so that reduced-form tests of LRN may be possible in practice. ${ }^{2}$ However, the two sets of authors come to different substantive conclusions, with Fisher-seater rejecting $L R N$ and King-Watson failing to reject it.

This paper revisits these controversies about the effects (both short-run and long-run) of monetary policy changes on the economy. In a 
departure from most of the previous literature we consider the empirical evidence for the liquidity effect and long-run neutrality together, rather than separately. Looking at the two propositions jointly allows us to ask questions like: Do there exist economically reasonable, dataconsistent models of the economy that exhibit both the liquidity effect and long-run neutrality simultaneously? To the extent that one has strong priors about the existence or magnitude of one of these two effects, then how do one's beliefs about the other proposition have to be modified in order to be consistent with the data? If we maintain that both propositions hold, how does that affect our views on issues such as the appropriate empirical indicator of monetary policy and the characterization of the Eed's operating procedures?

Like much of the recent literature, we address these issues in the context of vector-autoregressive (VAR) representations of policy and the economy. However, many VAR studies have based their findings on atheoretical permutations of the Wold causal ordering in the VAR and/or ad hoc identifications of monetary policy disturbances. In this paper, we impose additional discipline by working within the context of a structural VAR (SVAR) approach, as described further below, and we consider identifications based on both short-run and long-run restrictions.

As part of our analysis, we also explicitly address some common criticisms of the VAR literature, as they pertain to our application. These criticisms include insufficient attention to structural or parameter instability; uncertainty about the choice of policy indicator; and non-robustness of identification.

structural instability is among the most often-cited criticisms of VAR studies (again, see Rudebusch, 1997; Stock and Watson, 1995, document pervasive instability in macroeconomic relationships). Failure to allow for instability in the model structure or parameter values can, 
of course, lead to a mis-specification which renders the final results unreliable. To guard against this outcome we perform tests for structural shifts with unknown change point. Following stock and Watson (1995), we apply the Quandt (1960) likelihood ratio statistic in its Lagrange multiplier form. Overall, we find very little evidence of instability in our VAR. Interestingly, however, we do find instability in the covariance matrix of the VAR residuals. This result is predicted by our underlying economic model, as we discuss below.

A second key issue in the VAR literature is the empirical representation of changes in the stance of monetary policy. One explanation for the common finding of a protracted response of output, as well as for the failure to find statistically significant liquidity effect, is that shifts in monetary policy have typically been identified with movements in monetary aggregates. This way of measuring policy changes has been criticized on the grounds that, if the monetary authority follows some rule that admits accommodation of money demand shocks, then the broad measures of money contain an endogenous, nonpolicy component. ${ }^{3}$ For this reason, some recent studies of monetary phenomena have resorted to alternative measures of policy, based for example on interest rates or reserve aggregates. ${ }^{4}$ In this paper we take the approach to identifying monetary policy shocks developed by Bernanke and Mihov (forthcoming), which employs estimates of the parameters describing the market for bank reserves and the Fed's operating procedure to isolate innovations to policy. This method can accommodate passive adjustment by the Fed to changes in the demand for reserves; it has the additional advantage that its estimated parameters have economic interpretations, which allows us to restrict the space of parameter values which we are willing to consider.

The final criticism of VAR methods that we address is the possible non-robustness of identification. In this paper, we tackle this issue 
by relaxing the parameter restrictions proposed by Bernanke and Mihov. In particular, instead of focusing attention on the implications of a single set of point estimates, we consider a sequence of identification schemes satisfying economically-motivated inequality constraints. This estimation technique is in the spirit of robustness checks exemplified by the studies of Blanchard (1989) and King and Watson (1997). One advantage we have over the previous literature is that the nature of our structural model allows us to relate the long-run response of output to interpretable parameters describing short-run dynamics, thus linking directly the two fundamental propositions discussed above. In particular, we specify the space of admissible structural parameters and examine how the LE and LRN propositions fare as the parameters vary over that space.

The results support the view that the specific approach to identifying monetary policy disturbances is crucial for the estimated long-run properties of the model, as well as for the magnitude of the liquidity effect. More substantively, we find that, if monetary policy is identified by means of models of the class studied in Bernanke and Mihov (forthcoming), the LE and IRN "puzzles" largely disappear (although the statistical uncertainty surrounding LRN remains large). Since the Bernanke-Mihov model also performs well on other dimensions, including reasonableness of the implied parameter estimates and impulse responses, and in its ability to identify switches in policy regime at times that concur with conventional accounts (Bernanke and Mihov, forhcoming), we are encouraged to hope that our approach will prove useful in future analyses of monetary policy and its effects.

The remainder of this paper is organized as follows. The section to follow further motivates our analysis with a brief demonstration of why the LE and LRN propositions have had mixed support in previous empirical studies. In particular, we show that problems have arisen 
when innovations to monetary policy have been identified (inappropriately, in our view) with innovations to monetary aggregates. The third section of the paper undertakes the preliminary task of checking the stability of the VAR that underlies our estimation. The fourth section reviews the Bernanke-Mihov structural VAR methodology for identifying monetary policy innovations and presents estimates of a just-identified version of this model. In the fifth section we report the implications for LE and LRN of these estimates: We find that the LE and LRN propositions are not inconsistent with our approach to identifying monetary policy, although the point estimates for the output response imply what might be viewed as an "excessive" degree of persistence from the perspective of the LRN hypothesis.

The sixth major section of the paper investigates the robustness of these results by considering what happens when we identify the basic model only up to a set of economically-motivated inequality constraints. This exercise is a useful one, as it shows the combinations of beliefs about model parameters, the size of the liquidity effect, and the persistence of the responses of real variables to monetary policy shocks that are mutually consistent. The seventh section takes a different tack by imposing long-run neutrality restrictions to obtain identification of the model and studying the implications of these restrictions for the parameter values (including the direction and size of the liquidity effect). We conclude with a summary of the implications of this paper for VAR-based studies of monetary phenomena.

\section{Long-run neutrality and the liquidity effect: the empirical puzzles}

To motivate the subsequent analysis, we begin by reporting results from some standard VAR specifications that have been used in the literature. Our purpose is to illustrate in a simple way the two empirical conundrums discussed in the introduction, namely the 
surprising persistence of the output response to an innovation in the money supply and the apparent failure of the short-run liquidity effect. In particular, our results underscore the inadequacy of money aggregates as indicators of the stance of monetary policy. A simple demonstration of the LRN puzzle is shown in Figure $I$, which is based on bivariate VARs of money and output, with money ordered first. Data are quarterly, 1966 to 1996. Each row of the figure shows the impulse responses arising from a one-standard-deviation shock to the (nominal) monetary aggregate (M2, M1, and the monetary base MB in the first, second, and third rows, respectively). Output is measured by real GDP. The impulse responses are shown out to 40 quarters, and the dashed lines indicate twostandard-error bands. As all variables are in logs, the numbers on the vertical axes of each panel may be interpreted as indicating percentage deviations of each variable from the no-shock base case (i.e., 02 means a 28 deviation).

If we assume for the moment that orthogonalized innovations to money can be identified with shocks to monetary policy, Figure I suggests that the response of output to a monetary innovation is surprisingly protracted. The point estimates of the GDP responses at 40 quarters are similar to those at 8 quarters, and in two of the three VARs the response at 40 quarters is still significantly different from zero. If we take the impulse responses at their face value, the figure suggests that the economy never returns to its equilibrium path after a monetary shock, or at a minimum that the adjustment mechanism operates so slowly full adjustment takes more than ten years. This magnitude of the deviation from long-run neutrality contradicts most theoretical models of monetary business cycles, including those allowing channels for persistence. Parenthetically, note that the responses of the various monetary aggregates to their own shocks are also quite 
persistent, so that the Lucas-Sargent-McCallum critique discussed in the introduction does not necessarily apply.

Table I confirms the puzzle by means of another metric, the variance decomposition of forecast errors: We see that, at a ten-year horizon, innovations to the money stock apparently "explain" between half and four-fifths of the variance of the forecast errors for output! These are not numbers that we can take seriously, of course; they are presented only to illustrate the problems inherent in using monetary aggregates as measures of monetary policy.

Natural extensions of this simple bivariate system include adding more variables and experimenting with the lag structure and with the ordering. For example, adding a price variable (such as the GDP deflator) reduces the persistence of output response for some specifications, but the results are in general rather fragile, depending on which money and output measures are used. In addition, in these larger systems the long-run response of the price level to money shocks is typically less than proportional to the own response of money, contradicting the implication of LRN that real balances should be unaffected by monetary policy changes in the long run.

Further puzzles are raised by a more conventional four-variable VAR (see, e.g., Sims, 1980), including output, prices, money, and a short interest rate (here, the federal funds rate, in levels). Figures II (a), II(b), and II(c) show the effects of innovations to the money stock, where the money stock is measured by the base, MI, and M2, respectively, and the ordering of the variables in the VAR is as given in the captions to the figures. (Vertical scales continue to be measured in percentage deviations, except for the federal funds rate which is measured in percentage points.) For comparison to later results we show the responses of real balances (the log of the money 
stock minus the log of prices), although of course the underlying VAR is equivalent to one that includes nominal money and prices separately.

The results for the cases in which money is measured as the base or as M1 (Figures II(a) and II(b)) are particularly unappealing: First, although the output response is now less persistent, the direction of the short-run response is now "wrong" (a positive innovation to money is followed by a decline in output). Further, the response of the federal funds rate to a money shock is also in the "wrong" direction, rising instead of falling. This latter result illustrates the positive correlation of innovations to money and interest rates which underlies many rejections of the LE proposition.

It is interesting that the responses to a shock to M2 (Figure II(c)) look somewhat "better", in that the short-run responses of output and the interest rate have the right sign (Cochrane, 1994, notes these properties of M2). However, the very long-run responses of output and real balances still appear to be inconsistent with LRN. Further, it seems implausible to us that a broad monetary aggregate like M2, which depends so much on developments in the financial sector and the economy generally, would be a better indicator of policy actions than, say, the monetary base. Hence, we should not necessarily conclude from Figure II(c) that M2 is a useful indicator of monetary policy.

As the literature has recently begun to recognize, the endogeneity of the money stock is likely a major reason for the counterintuitive results displayed in Figures I and II. For example, the positive shortrun correlation of innovations to money and to interest rates (which underlies some rejections of LE) probably reflects the endogenous response of the Fed to money demand shocks, under regimes in which there is some degree of interest rate smoothing. Similarly, the correlation of money and output in the long run may arise from the Fed's accommodation of increases in money demand associated with permanent 
shocks to output arising from non-monetary sources. Thus, exercises like the ones presented here should convince us that, instead of experimenting with the orderings, lags, or lists of variables in the VAR, we should instead think a little bit more carefully about identification problems.

One attempt along these lines is by King and watson (1997). Emphasizing that the measurement of long-run phenomena may very much depend on the correct identification of contemporaneous relationships, they suggest a methodology of selecting a plausible range for the impact elasticities of money and output. They then explore the sensitivity of the long-run response of output to "admissible" changes in these shortrun parameters. We consider their approach to be very informative, and below we apply this technique within the framework of the model developed in Bernanke and Mihov (forthcoming). An advantage of using a structural model, like the Bernanke-Mihov model, in this context is that the model parameters have direct economic interpretations; therefore we can use economic reasoning and prior information to restrict the space of admissible identification schemes. More generally, the BernankeMihov framework explicitly addresses the issue of identifying innovations to monetary policy when Federal Reserve actions, and hence the money stock, are partially endogenous. Thus this approach may provide a means of avoiding the anomalies shown in Figure I and Figure I.

\section{stability analysis}

As just noted, Bernanke and Mihov (forthcoming) use a small structural model of the market for bank reserves to identify monetary policy shocks. Estimation of that model proceeds in two steps: First, a reduced-form VAR (in monthly data) containing the variables of interest 
is estimated. Second, following the conventional SVAR methodology, a structural model is used to interpret the covariance matrix of VAR residuals obtained from the first-stage estimation. As we will want to rely heavily on that model in the subsequent sections to study both short-run and long-run relationships, it is important to know the extent to which the estimates are structurally stable. Here we briefly report the results of a preliminary analysis of the stability of the two major inputs to the estimation, namely, the dynamic relationships embodied in the first-stage VAR, and the contemporaneous covariance matrix of the VAR residuals.

The setup of the Bernanke-Mihov model requires that the vector of endogenous variables includes total bank reserves, nonborrowed reserves, anci the federal funds rate, which we refer to collectively as policy variables. In addition, to study the dynamics of output and prices we follow our earlier work in including interpolated monthly series of GDP and the GDP deflator. ${ }^{5}$ We add to the VAR an index of spot commodity prices, which has been found by Sims (1992) and by Christiano, Eichenbaum and Evans (1994, 1996) to help solve the so-called "price puzzle". Finally, because we want to study the effects of policy shocks on real balances, we also add M2 (written in real terms) to the VAR (this variable was not included in Bernanke and Mihov, forthcoming). Thus the VARs we consider include as the "non-policy variables" log real GDP (GDP), the log GDP deflator (PGDP), the log commodity price index (PCOM), and $\log$ real balances M2/PGDP; and the set of policy variables consisting of total reserves (TR), nonborrowed reserves (NBR), and the federal funds rate (FFR). Total reserves and nonborrowed reserves are measured in levels, relative to a long moving-average trend, for reasons discussed in Bernanke and Mihov (forthcoming).

We consider first the stability of the reduced-form, or firststage, VAR. We selected lag lengths by applying the Akaike information 
criterion to candidate models using 6 to 18 sequential monthly lags, finding evidence for a 7-lag specification. It is interesting that adding M2 to the system seems to significantly reduce the number of lags required in the VAR; Bernanke and Mihov (forthcoming) used the AIC to choose a lag length of 13 in VARs excluding M2.

The stability analysis is performed by applying the Lagrange multiplier version of the Quandt (1960) likelihood ratio test with heteroskedasticity-robust weighting matrix (see also Andrews, 1993 ). This is a test for break points in the model structure, for which (unlike some traditional tests) the break point does not have to be specified a priori. The choice of the LM version of the test was based on a small Monte Carlo study which showed, in particular, that this version does extremely well for autoregressive processes with roots close to unity (as is the case in our application). Additional Monte Carlo studies showed that the wald version of the test rejects the null too often in settings like ours. The likelihood ratio version of the Quandt test had similar performance to the LM-based test; we chose the latter for its relative computational simplicity. Using this test on our 7-variable system with 7 lags gave us no grounds to reject stability of the system for our 1966-1996 sample. Bernanke and Mihov (forthcoming) found a similar result for their 6-variable system with 13 lags. It is admittedly somewhat surprising (although also convenient) that the stability of the VAR over such a long period cannot be rejected; it may be that the small number and aggregative nature of the variables obscures the effects of structural changes that have occurred at the microeconomic level over the past three decades.

A second potential source of instability is the variancecovariance matrix of the VAR residuals. In particular, we focus here on the VCV matrix of the orthogonalized VAR residuals from the "policy block", which are the basis of the model's structural estimates. 
Bernanke and Mihov (forthcoming) use switching-regression techniques to study the stability of the model's structural parameters, which are determined by the VCV matrix of VAR residuals. They report that there is strikingly precise statistical evidence for a switch in the model parameters (and, by implication, in the residual VCV matrix) in 1979 and again in 1982, dates corresponding to well-known changes in the operating procedures of the Fed. Here we follow a somewhat different approach: Instead of testing the stability of structural parameters, we consider directly the elements of the variance-covariance matrix of the orthogonalized residuals from the "policy" block (including the two reserves variables and the federal funds rate). Since this block involves three variables, the covariance matrix consists of six distinct elements, which are tested serarately for stability, again using the LM version of the Quandt test.

With this procedure the first break we determine occurs in 1979:10 (a rather remarkable end date to find by a purely statistical procedure, given that Chairman Volcker's new operating regime was announced in october 1979). Thus we find no evidence of a break in the VCV matrix for the period 1966:1-1979:9. There is also no statistically significant break between 1979:10 and 1982:4, and no break after 1988:3. There are however several significant breaks between 1982:4 and 1988:3. These break dates correspond well to the dates of putative changes in the Fed's operating regimes, including the gradual evolution from targeting nonborrowed reserves to borrowed reserves to the federal funds rate over the mid-1980s. Indeed, the structural model we use implies that breaks should be observed when operating regimes change. The existence of multiple operating regimes is potentially an important caveat for statistical analyses of monetary policy, as stressed by Bernanke and Mihov (forthcoming). 
With these preliminary results in hand, we now turn to the estimation and analysis of our structural VAR model of the market for bank reserves.

\section{The Model of the Market for Bank Reserves ${ }^{6}$}

Above we showed that incongruous results follow from VARs that use the assumption that the money stock is exogenous with respect to output, prices, and interest rates. We noted that these results should no longer surprise us, as the endogeneity of the growth rates of monetary aggregates, and hence their inappropriateness as policy measures, is now well recognized. In particular, it is clear that as long as the Fed follows some policy of accommodating money demand shocks, the growth rates of monetary aggregates will reflect changes in money demand (either exogenous shifts, or changes induced by changes in macro variables) as well as changes in policy. Secular changes in velocity brought about by financial innovation, deregulation, and other factors are a further barrier to using money growth rates alone as a measure of the direction of policy.

In an attempt to avoid the problem of money-stock endogeneity, several studies have attempted to construct indicators of monetary policy stance that are based on interpretations of the Federal Reserve's operating procedures. Some recent examples include Bernanke and Blinder (1992), who propose using the federal funds rate as a measure of monetary policy stance; Christiano and Eichenbaum (1992) (see also Eichenbaum, 1992), who argue for the quantity of nonborrowed reserves as an indicator; and strongin (1995), who suggests using the portion of nonborrowed reserve growth that is orthogonal to total reserve growth. Sstrongin's justification is that the Fed is constrained to meet total reserve demand in the short run but can effectively tighten policy by 
reducing nonborrowed reserves and forcing banks to borrow more from the discount window).

Bernanke and Mihov (1995, forthcoming) develop a framework for evaluating these competing measures and for developing new ones, following the "semi-structural" VAR methodology of Bernanke and Blinder (1992). As foreshadowed in the previous section, their application of this approach assumes that the variables of interest can be broken up into two blocks: (1) "non-policy" macroeconomic variables and (2) policy-related variables. Bernanke and Mihov show that, in order to study the effects of policy changes in this framework, one need not specify the whole economic structure; instead, identification of policy effects can be achieved through specification of only (1) the structural relationships among the policy variables and $(2$; the direction of contemporaneous effects between the policy and non-policy blocks of variables. In general, these contemporaneous effects have the interpretation of information flows (Sims, 1986; Sims and Zha, 1995; Leeper, Sims and Zha, 1997). Here we make the assumption that the innovations to policy variables do not feed back to the economy within a period.

Incorporating this timing assumption, we can write a general linear structural model incorporating both the non-policy and policy variables as:

$$
\begin{aligned}
& \mathbf{Y}_{t}=\sum_{i=0}^{k} \mathbf{B}_{i} \mathbf{Y}_{t-i}+\sum_{i=1}^{k} \mathbf{C}_{i} \mathbf{P}_{t-i}+\mathbf{A}^{y} \mathbf{v}_{t}^{y} \\
& \mathbf{P}_{t}=\sum_{i=0}^{k} \mathbf{D}_{i} \mathbf{Y}_{t-i}+\sum_{i=0}^{k} \mathbf{G}_{i} \mathbf{P}_{t-i}+\mathbf{A}^{p} \mathbf{v}_{t}^{p} .
\end{aligned}
$$


where $\mathbf{Y}$ and $\mathbf{P}$ are vectors of non-policy and policy variables, respectively, and the $\mathbf{v}^{\prime}$ 's are mutually orthogonal structural

disturbances. In particular, assume that one of the $\mathbf{v}^{\prime} \mathbf{s}$, call it $v^{s}$, represents the innovation to the stance of monetary policy that we are attempting to recover. Likewise, the impulse response functions of observable variables with respect to this policy shock are estimates of the dynamic responses of macro variables to unforecasted changes in monetary policy stance.

The system $(1)-(2)$ can be put into standard VAR form by projecting the vector of all contemporaneous variables on $k$ lagged values of itself. Let $\mathbf{u}^{p}$ represent the vector of VAR residuals from the policy block, orthogonalized with respect to the VAR residuals from the nonpolicy block. It follows that a straightforward calculation that $\mathbf{u}_{?}^{p}$ satisfies

$$
\mathbf{u}_{t}^{p}=\left(\mathbf{I}-\mathbf{G}_{0}\right)^{-1} \mathbf{A}^{p} \mathbf{v}_{t}^{p}
$$

where the variables on the right-hand side of (3) are as defined in (2). Alternatively, dropping subscripts and superscripts, we can rewrite (3) as :

$$
\mathbf{u}=\mathbf{G u}+\mathbf{A v}
$$

Equation (4) represents a structural VAR (SVAR) system, which relates observable VAR-based residuals $\mathbf{u}$ to unobserved structural shocks $\mathbf{v}$, one of which is the policy shock $v^{s}$. As Bernanke and Mihov 
show, this system can be identified and estimated by conventional methods, allowing recovery of the structural shocks, including $v^{s}$.

To make further progress empirically, it is necessary to specify an explicit structural model, of the form of (4), relating the VAR residuals from the policy block and the (unobservable) structural disturbances. Bernanke and Mihov propose using a standard model of the market for federal funds. In innovation form (that is, with the lags "swept out" by a first-stage reduced-form VAR), this model can be described by the following three equations:

$$
\begin{aligned}
& u_{T R}=-\alpha u_{F F R}+v^{d} \\
& u_{B R}=\beta\left(u_{F F R}-u_{D I S C}\right)+v^{b} \\
& u_{N B R}=\phi^{d} v^{d}+\phi^{b} v^{b}+v^{s}
\end{aligned}
$$

The interpretation of this system is the following (see BernankeMihov, 1997, for more details): Equation (5) represents the total demand for reserves by commercial banks; it states that the innovation in the demand for total reserves depends (negatively) on the innovation in the federal funds rate (the price of reserves) and on a structural demand disturbance, $v^{d}$. Equation (6) determines the portion of reserves which banks choose to borrow at the discount window: The demand for borrowed reserves (in innovation form) is assumed to depend positively on the innovation in the federal funds rate and negatively on the innovation to the discount rate; $v^{b}$ is a disturbance to the borrowing function. Equation (7), a particularly important component of the specification, describes the behavior of the Federal Reserve. According to (7), in setting (the innovation to) the supply of nonborrowed reserves, the Fed is allowed to observe the innovations to the demand for total reserves * 
and the demand for nonborrowed reserves, and to respond to these innovations to a degree determined by the coefficients $\phi^{d}$ and $\phi^{b}$ (note that these two coefficients could be zerol. The portion of the change in nonborrowed reserves which is unrelated to the Fed's passive accommodation of disturbances in the federal funds market, $v^{s}$, represents the pure policy disturbance we are attempting to identify. It will also be useful to write the reduced-form relationship between the VAR residuals $\mathbf{u}$ and the structural disturbances $\mathbf{v}$, as in equation (3). To do so, we make the simplifying assumption that the innovation to the discount rate $u_{\text {DISC }}$ is zero. ${ }^{B}$ The model is then solved by imposing the condition that the supply of nonborrowed reserves plus borrowings must equal the total demand for reserves. Solving in terms of innovations to total reserves, nonborrowed reserves, and the federal funds rate, we have an equation in the form of (3), where

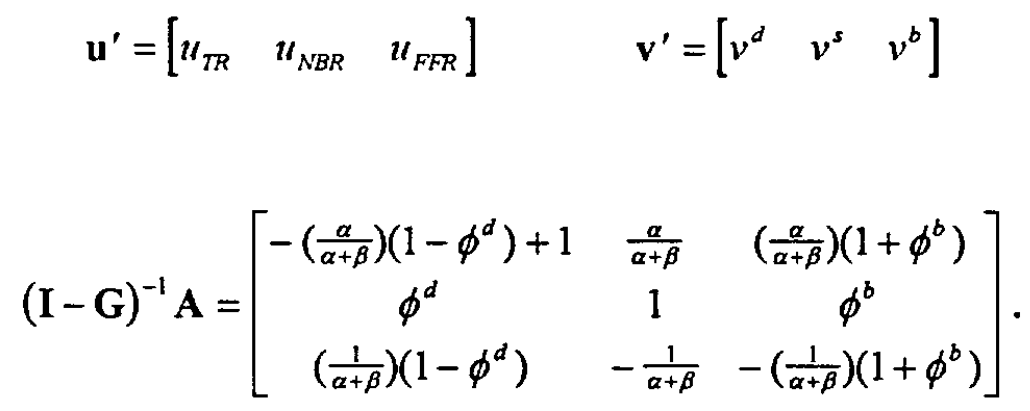

One can also invert the relationship (8) to determine how the monetary policy shock $v^{s}$ depends on the VAR residuals. The result is:

$$
v^{s}=-\left(\phi^{d}+\phi^{b}\right) u_{T R}+\left(1+\phi^{b}\right) u_{N B R}-\left(\alpha \phi^{d}-\beta \phi^{b}\right) u_{F F R}
$$

The model described by equation (7) has seven unknown parameters (including the variances of the three structural shocks) to be estimated 
from the six observable covariances of the policy-block VAR residuals. Hence, in general the model is under-identified by one restriction. There are several ways to proceed:

One approach is to note that some of the simple indicators of monetary policy proposed in the literature can be interpreted as imposing additional identifying restrictions on this general model. For example, the Bernanke-Blinder (1992) proposal to use the federal funds rate as a policy indicator is valid in this model under the additional parameter restrictions, $\phi^{d}=1, \phi^{b}=-1$. Similarly, the nonborrowedreserves measure proposed by Christiano and Eichenbaum (1992) and the reserves-based measure proposed by Strongin (1995) also each impose two additional parameter restrictions to our basic model. (These restrictions are $\phi^{d}=0, \phi^{b}=0$ for the Christiano-Eichenbaum model and $\phi^{b}=0, \alpha=0$ for the Strongin model; see Bernanke-Mihov, forthcoming, for discussion.) Thus, imposing that one of these specific indicators is correct over-identifies the model by one restriction. Bernanke and Mihov use this fact to obtain estimated parameter values, as well as to test the consistency of the proposed indicators with the data, conditional on their basic model of the reserves market. 9

An alternative strategy is to attempt to motivate one additional parameter restriction, so that the model can be just-identified. Following Strongin's (1995) argument that, for institutional reasons, the short-run demand for reserves is inelastic, Bernanke and Mihov (forthcoming) experiment with the restriction that $\alpha$ (the slope of the demand curve for total reserves) is zero. The estimates obtained from this model imply a new monetary policy indicator, which can be thought of as a hybrid of the simple indicators proposed in the literature, with weights determined by the estimated values of the parameters (especially the Fed's reaction parameters, $\phi^{d}$ and $\left.\phi^{b}\right)$. The results from 
estimating this model seem quite reasonable: Bernanke and Mihov find that, consistent with the conventional wisdom, there is evidence that the Fed targeted nonborrowed reserves during the 1979-1982 Volcker experiment period, but has focused on interest-rate targeting for most of the post-1965 period, especially prior to 1979 and after 1988 . On average, they found that the Fed has tended to accommodate the bulk of reserves demand shocks and a substantial portion of borrowings shocks. Their estimates also generally implied a statistically significant liquidity effect.

New estimates of the just-identified version of this model for the full 1966-96 sample and some sub-samples are given in Table II. Subsample estimates are based on the covariances of the residuals for that sub-sample as derived from the full-sample VAR, which is valid since we have not rejected full-sample stability of the first-stage VAR. As in Bernanke and Mihov (forthcoming), estimation was carried out by means of an efficient two-step GMM procedure: The first step of the procedure was equation-by-equation OLS estimation of the coefficients of the VAR system. The second step involved matching the second moments implied by the theoretical model being estimated to the covariance matrix of the "policy sector" VAR residuals (suitably orthogonalized).

The estimates in Table II are not identical to those of BernankeMihov (forthcoming), principally because the first-stage VAR used in this paper is different (we have added real balances and employed fewer lags). Nevertheless, qualitatively the results are quite similar to those of the earlier paper. In particular, we find considerable evidence of interest-rate smoothing $\left(\phi^{d}>0, \phi^{b}<0\right)$ for the sample as a whole and for the pre-1979 period (as argued by Bernanke and Blinder, 1992). The smallest amount of interest-rate smoothing occurs during the 1979-82 "Volcker experiment", during which nonborrowed-reserves 
targeting $\left(\phi^{d}=0, \phi^{b}=0\right)$ cannot be statistically rejected. During the post-1982 period, we again see considerable evidence of interest-rate smoothing, at least with respect to reserve demand shocks ( $\phi^{d}$ is about $0.7)$; the response to borrowed-reserves shocks after 1982 is hard to identify, probably because of the greatly decreased importance of discount-window borrowing in the monetary control process during that period.

Since the just-identified model seems to work well, and it implies an indicator of monetary policy that encompasses a number of simpler indicators, we work with the just-identified model (imposing $\alpha=0$ ) in some of the analyses below. In the next section we first consider the long-run estimated effects of monetary policy innovations as implied by the estimates of the just-identified model. In principle, if the model is correct, this approach should circumvent the problem of endogenous money aggregates, allowing us to observe the responses of the economy to a genuinely exogenous policy shock. Below, in order to analyze the robustress of these results, we consider the long-run effects of monetary policy shocks when the model is identified only up to inequality restrictions. We also consider below the effects of identifying the model by imposing restrictions on the long-run responses of output and real balances to a monetary policy shock.

\section{The LRN and IE Propositions: A Second Look}

With this background, we are now in a position to examine whether the endogeneity of money measures used in some previous literature is behind the variable empirical support that has been obtained for longrun neutrality (LRN) and the liquidity effect (IE). As a first pass we use the just-identified model described in the previous section to 
isolate the monetary policy disturbances, on which the estimated responses of output and interest rates are based.

We consider first the implications of the estimated model for long-run neutrality. Figure III displays the impulse responses of two endogenous variables in the system, output and real balances, to an "expansionary" monetary policy shock. ${ }^{10}$ The magnitude of the shock is normalized to correspond to a 18 deviation of nonborrowed reserves above its trend in the zero-th period. Figure III also shows p-values for the hypotheses that the responses of output and real balances at each horizon are different from zero. Figure IV shows the response of the federal funds rate to the same policy shock.

The results shown in Figures III are certainly more consistent with the LRN hypothesis than those of Figures I and II. The response of output to the policy shock is hump-shaped, peaking at two years and then declining. At four years the output response is no longer statistically different from zero. It is a bit troubling however, that the point estimates of the output response remain above zero even at the ten-year horizon; below we consider the implications for our estimated model of "forcing" the output response to be zero asymptotically. Although nominal money and the price level individually have non-stationary responses to an identified policy shock (not shown), Figure III shows that their ratio, real M2 balances, peaks rather quickly and returns almost precisely to zero after about five years. ${ }^{11}$

Conditional on the just-identified model, there is also evidence of a statistically significant liquidity effect (Figure IV): the initial impact of a monetary policy shock that induces a 18 increase in nonborrowed reserves is about a 40-basis-points drop in the fed funds rate, increasing to about 60 basis points within 1-2 months. The deviation from trend lasts for about nine months. This finding in a VAR context has also been documented for the full sample by other 
researchers using different policy identification schemes (see for example Christiano, Eichenbaum, and Evans, 1994b, and Strongin, 1995). Under their identifications, however, the liquidity effect essentially vanishes for samples that start after 1982. We will address this issue below and show that although the magnitude of the liquidity effect may have decreased in the last fifteen years, it is still non-zero under a wide variety of assumptions about the values of the structural parameters.

So, using estimates of the model of the market for bank reserves as a basis for identifying policy shocks, we have found evidence supporting the liquidity effect and long-run neutrality (although, with respect to the latter, the fact that the point estimates of the output response remain non-zero at long horizons is worrisome). However, one may feel justifiably concerned about drawing strong conclusions based on a single set of point estimates, particularly since the estimates are based entirely on short-run (monthly) correlations (Sarte, 1997). To increase confidence in both the model and the results, we turn now to some further refinements of the policy identification scheme.

\section{Inequality Restrictions and the Admissible set of Parameters}

In their study of long-run neutrality, King and Watson 11997; first circulated in 1993) introduce an innovative approach for studying the sensitivity of the empirical results to different identification restrictions. Instead of imposing a single set of restrictions to identify their model, they report results for a wide range of parameter values, all of which produce observationally equivalent models. Their exercise provides a more precise conclusion about the dependence of long-run phenomena on short-run partial correlations. 
In this section we employ a similar approach. However, the fact that we start from a structural model allows us to impose interpretable boundary restrictions on the manifold of structural parameters.

As previously noted, the general model of the bank reserves market is under-identified by one restriction. In the previous two sections we used the identification assumption that the short-run demand for bank reserves is inelastic $(\alpha=0)$. Now we relax this restriction and instead consider the effects of imposing the following set of inequality constraints:

$$
\begin{aligned}
\alpha & \geq 0 \\
\beta & \geq 0 \\
\phi^{d} & \geq 0 \\
\phi^{b} & \leq 0
\end{aligned}
$$

These inequality constraints are economically motivated and impose weak restrictions on our specification, equations (5)-(7). Inequality (10) states that the demand curve for total reserves should slope down; (11) imposes an upward-sloping borrowing function (in borrowings-funds rate space); (12) and (13) impose that the Fed either smoothes interest rates or does not respond to reserves-market disturbances, i.e., the Fed does not actively seek to amplify the effects on interest rates of shocks to reserves demand or borrowings. Note that a variety of operating procedures are encompassed by these restrictions (see Bernanke and Mihov, forthcoming).

Inequalities (10) and (11) also imply that the range of admissible values for the contemporaneous liquidity effect, which we will define as the impact effect on the nominal interest rate of a policy shock that induces a 18 decline in nonborrowed reserves is 
$[0,+\infty)$. This follows from the fact that the within-period liquidity effect is $\frac{1}{\alpha+\beta}$, which is the $(3,2)-$ th element of the matrix in equation (8). The lower bound of the instantaneous liquidity effect is achieved when either the borrowings function or the demand schedule is infinitely elastic, while the upper bound requires that both schedules are vertical. Note that, although the instantaneous liquidity effect is restricted to have the "right" sign (or be zero), the model does not place restrictions on the response of interest rates after the zero-th period.

An interesting question is whether we can relate the estimates of the magnitude of the liquidity effect and of the long-run responses of output and other variables to a policy shock. As it turns out, there is a direct relationship between these two phenomena, which should warn us that identification restrictions that produce different liquidity effects will have different implications for long-run monetary neutrality as well.

Before examining the estimates from a sequence of models satisfying the restrictions above, we should discuss two more issues. First, note that the system of structural equations used in the estimation is of the form $E\left[\mathbf{A v v}^{\prime} \mathbf{A}^{\prime}\right]=E\left[\mathbf{u} \mathbf{u}^{\prime}\right]$, where $E[\cdot]$ is the expectations operator and the other elements are defined in (8). This expression represents a system of quadratic equations in the structural parameters. An analytical solution of this system is given in an appendix available from the authors; here we point out only that sometimes this solution (subjected to the constraints $(10)-(13)$ ) produces two roots. This multiplicity slightly complicates the problem. However, in practice both roots are quite interesting and interpretable. The second issue is how exactly to present the results of the estimation. We perform literally hundreds of estimations, and a 
parsimonious way of communicating the findings is essential. One possibility is to use one of the four parameters listed in (10)-(13) as an anchor variable, and to slide over the possible set of values for this parameter while reporting what happens to the other three parameters. This is not an unreasonable strategy. Its drawback is that there is no clear guideline as to what the plausible set of values is. An alternative presentation strategy, which we use here, is to look at alternative values of the liquidity effect, $\frac{1}{\alpha+\beta}$. All results below use the magnitude of the liquidity effect to pin down movements along one of the axes. As noted, the liquidity effect is measured as the number of basis points that the funds rate rises when there is a monetary policy shock that leads nonborrowed reserves to fall 18 below trend.

Now we can turn to the results. Figure $V$ displays in graphical form the estimates of the structural parameters from the standard SVAR described in the previous subsection. ${ }^{12}$ The structural model has been solved for any given liquidity effect, with solutions falling outside the parameter space described by (10) through (13) being discarded. There are many interesting results reported in this figure. First, it seems that for any meaningful identification scheme in our model there is a non-trivial liquidity effect. The range for the liquidity effect is between 24 and 48 basis points (recall that a contemporaneous liquidity effect of zero is admissible in principle under our scheme). The lower bound for the liquidity effect is obtained when $\phi^{d}$ is equal to zero, i.e. when the Eed does not react contemporaneously to reserves demand shocks, while the upper bound is achieved when identification eliminates the multiplicity of the roots. That is, a liquidity effect below 24 basis points is inconsistent with inequality (12) and therefore would require that the monetary authority propagates or reinforces 
reserves demand shocks, while values for the liquidity effect above 48 basis points produce complex values for the estimates of the structural parameters.

Second, within a certain range for the liquidity effect (between 43 and 48 basis points), there are two roots solving the system of quadratic equations that define the parameter values, as indicated by the solid and dashed lines. Call the solid line root one and the dashed line root two. Although the second root (dashed line) occupies a smaller portion of the parameter space, this is where three of the four identification schemes discussed in section 4 focus. Namely, this is the root that corresponds more closely to the Bernanke-Blinder, Strongin, and Bernanke-Mihov models, while the other root corresponds to the Christiano-Eichenbaum scheme (recall that this mode: imposes a zero restriction on the parameter capturing Fed's accommodation of demand disturbances, i.e., $\phi^{d}=0$ ). ${ }^{13}$ Figure $\mathrm{V}$ also makes obvious why the nonborrowed reserves measure does not perform very well in terms of the over-identification tests reported in Bernanke and Mihov (forthcoming): The other restriction of that model is $\phi^{b}=0$, which seems to be inconsistent with the data for any admissible choices of the other parameters.

Third, Figure $V$ illustrates that the estimated size of the liquidity effect depends crucially on the identification scheme. For example, an "atheoretical" VAR that includes total reserves and nonborrowed reserves and employs a recursive ordering to identify the system will produce two very different results by a simple switch of the order of the reserve variables: When nonborrowed reserves are ordered first, then the implicit assumption is that $\phi^{d}=0$, so that the estimates will be in the "left" corner of the parameter space (see the third panel of Figure $V$ ) and the estimated liquidity effect will be 
small. In contrast, ordering total reserves before nonborrowed reserves is tantamount to imposing that demand curve is inelastic $(\alpha=0)$, leading to a solution in the "right" corner of the space, with the implication that the estimated liquidity effect will be high.

We can also use this framework to investigate the range of longrun responses of output and real money balances to a policy shock, as a function of the (admissible) liquidity effect. These results are shown in Figures VI and VII, each of which has two parts. We report results for both the first root (solid ines) and the second root (dashed lines) where applicable. Each panel in the left columns of Figures VI and VII represents a different horizon, and relates the output response (Figure VI) and real balances response (Figure VII)) at that horizon to the assumed instantaneous liquidity effect (shown on the horizontal axis).

We see that the departure of the output response from zero is positively related to the liquidity effect at every horizon (Figure VI). The associated p-values for the output response are monotonically declining in the liquidity effect. So, the smaller the liquidity effect we are willing to accept, the easier it is to accept the hypothesis of long-run neutrality as well. However, note that for a horizon of three years, the LRN hypothesis is consistent with estimated values of the liquidity effect less than 40 basis points or so, and at five years or more LRN is not contradicted by any magnitude of the liquidity effect within the admissible range.

Figure VII shows, analogously, the response of real balances as a function of the horizon and the assumed liquidity effect. For real balances, the requirement of IRN does not much restrict the range of liquidity effects that can be considered; indeed, the response of real balances is statistically indistinguishable from zero at three years for all admissible values of the liquidity effect, and the point estimates of the response also go nearly uniformly to zero for any value of the 
liquidity effect. However, in this case the shorter-run responses are also interesting: Note that for smaller values of the liquidity effect, the response of real balances at one-to-three year horizons has the "wrong" sign (an expansionary monetary shock leads to a decline in real balances). The sign of the response is "correct" only for relatively high values of the liquidity effect. This finding weakens the case for accepting a value of the liquidity effect near the lower end of the admissible range.

We have been using the implied responses of output and real balances to assess the plausibility of various ranges of values for the short-run liquidity effect. A way to formalize this procedure is to simply impose LRN as an identifying restriction and see what the implications are for the parameter estimates and the size of the liquidity effect. We do this in the next section. Before proceeding further, however, we can use the apparatus of this section to discuss the phenomenon of the so-called "vanishing liquidity effect" after 1982 (see Christiano, 1995, Pagan and Robertson, 1995). The analysis thus far demonstrates that the magnitude of the estimated liquidity effect may depend very much on the identification scheme employed in the particular VAR (Bernanke and Mihov, forthcoming, discuss this issue and calculate the bias in the estimated liquidity effect that is obtained when the "wrong" measure of monetary policy is used).

Figure VIII, also in two parts, is analogous to Figure $V$ in showing the space of admissible (data-consistent) structural parameters for the Bernanke-Mihov model, but it shows these results for pre-1979 and post-1982 sub-samples separately. (For this exercise we have reestimated the first-stage VAR for each sub-sample and used the associated, "partial-sample" residuals. The alternative procedure, using the residuals for each sub-sample from the VAR estimated over the 
full sample, gives very similar results.) Comparison of the two parts of Figure VIII does suggest that the liquidity effect has become smaller in the years since 1982: The maximum liquidity effect that is consistent with the admissible parameter ranges is around 37 basis points in the period between 1965 and 1979, while it falls to some 23 basis points in the post-1982 period; and indeed, the model is consistent with there being no liquidity effect at all in the post-1982 sample, in that zero is an admissible value in Figure VIII(b). ${ }^{14}$

However, it is also interesting to note that the lower bound of the value of the liquidity effect in every period is achieved under the identification that $\phi^{d}=0$, i.e., that the Fed does not smooth out the effects of reserves demand shocks. This observation sheds light on the finding in Christiano (1995) that a 18 increase in NBR actually leads to an increase in the federal funds rate: The ordering of the VAR in his paper implies that the innovations to NBR (suitably orthogonalized) reflect only money supply shocks, which corresponds to the restriction that $\phi^{d}=0$ (as well as $\phi^{b}=0$ ) in our context. Hence, from the perspective of the model estimated here, Christiano is implicitly forcing his estimates into the left corner of the parameter space shown in Eigure VIII(b), with the result that he finds little evidence of a liquidity effect. Thus, to some extent, the "vanishing liquidity effect" reflects a particular choice of identification assumptions, specifically that innovations to monetary policy can be identified throughout the sample with innovations to nonborrowed reserves. (Note from Figure VIII(a) that this assumption does not imply a zero liquidity effect in the pre-1979 period.l

Despite this quibble, we must still agree that there is some evidence for a decline in the magnitude of the liquidity effect, in that the admissible range for this value declined significantly during the 
1980s. Assuming that this result holds up statistically, we face the puzzle of why such a shift occurred. There is one suggestive piece of information in Figure VIII, which is that it appears to be variation in the slope of the demand curve for reserves $(\alpha)$ rather than in the slope of the borrowings function $(\beta)$ which accounts for most of the observed decline in the liquidity effect: While the estimated value of $\beta$ does not differ much from about 0.02 in both sub-samples, the range of values for $\alpha$ is about $(0,0.06)$ in the earlier period but is not restricted within its theoretically admissible range of $[0,+\infty)$ within the latter period. It appears that the search for causes of the decline in the liquidity effect might do well to focus on the behavior of commercial banks, and in particular the effects of changes in reserve accounting procedures, deregulation, and financial innovation on the elasticity of the demand for reserves.

\section{Identification of the Model by Long-Run Restrictions}

The previous section studied how changes in the identification of short-run relationships in the model affect the estimated long-run response of output. This section takes the opposite tack: It considers what happens when we impose IRN as an identifying restriction. In particular we ask what imposing LRN does to the estimated parameters of the model and to the estimated size of the liquidity effect.

To just-identify the model in the earlier estimations reported in this paper, we imposed the condition that the demand for reserves is vertical $(\alpha=0)$. In the section just preceding we considered a range of possible identifications of the model, conditional on assumed (admissible) values of the liquidity effect. Now we relax all of these 
assumptions and ask what happens when instead we impose that the responses of output and real balances go to zero in the long run. Since the basic model is under-identified by one restriction when we do not assume that $\alpha=0$, the two IRN restrictions over-identify the model by one restriction. Thus in principle we can test the over-identifying restriction.

We discuss our estimation procedure briefly. To impose the two long-run restrictions, we take an approach similar to that of Blanchard and Quah (1989), except that unlike those authors we use short-run and long-run identifying restrictions simultaneously. ${ }^{15}$ we begin by rewriting our first-stage VAR so that real output and real balances enter in log first-differences, instead of log-levels; this amounts to imposing a restriction on the lag structure of the VAR. We then rewrite the system again in error-correction form, so that one lag of the loglevels of output and real balances appear on the right side; this step imposes no additional restrictions. The requirement that monetary policy shocks have no long-run effects on output or real balances is equivalent to restrictions that certain linear combinations of the coefficients on the error-correction terms be equal to zero. These linear combinations depend in turn on the full set of estimated parameters. Thus, unlike our previous estimations, full efficiency requires simultaneous estimation of the "first-stage" VAR and the structural model.

While such simultaneous estimation is straightforward in principle, the large number of parameters in the first-stage VAR makes a one-step approach computationally infeasible. We therefore estimate the VAR and the structural model in two stages, that is, sequentially. As long as the over-identifying restriction is true (and, as we will see, the evidence against it is very weak), the results will still be 
consistent; indeed, we are reasonably confident that our estimates are close to the fully efficient estimates.

The results of this estimation are reported in Table III, for the full sample and for three sub-periods suggested by our earlier tests of parameter stability. For each sub-sample, the first row shows the results when no inequality restrictions are placed on the parameter values. In some cases this unrestricted estimation led to (slightly) negative estimated values of $\alpha$, so for each sub-sample the second row reports results for which $\alpha$ is constrained to be positive. The last two columns show the implied estimated values of the liquidity effect (in basis points) and the p-values for the test of the over-identifying restriction.

The results are perhaps what we should have expected, given the cautions of Faust and Leeper (1997) about the informativeness of longrun restrictions, as well as the large standard errors observed earlier for the estimated long-run responses of output and real balances. Although the parameter estimates and estimates of the liquidity effect are reasonable and similar to our previous results, the estimates have higher standard errors than the estimates presented in Table II. In particular, the parameter measuring the Fed's response to borrowing shocks, $\phi^{b}$, is poorly identified in all sub-periods, and the response of the Fed to shocks to reserves demand, $\phi^{d}$, is poorly identified in the 1982-1996 sub-sample (although not in the 1988-1996 sub-sample). There is also no evidence for rejecting the over-identifying restriction. Overall, the long-run restrictions appear to do little to tie down the identification of our short-run model. On the other hand, this result also says that a prior belief in long-run neutrality provides no basis for rejecting our specification. 
There are other ways to impose long-run restrictions which may provide relatively more information and should be pursued in future research. Instead of imposing a zero response of output and real balances only asymptotically, for example, one might take a stronger stand about the time frame over which LRN should hold. Following a suggestion by Faust and Leeper (1997), one possibility is to impose the restriction of zero response at a given finite horizon and at all subsequent points. For example, one might consider imposing long-run neutrality by imposing that the output response is exactly zero at 60 months, 61 months, 62 months, etc. This of course implies overidentification since there are in some sense an "infinite" number of parameter restrictions. However, these restrictions could be weighted by the usual GMM methods, with restrictions at distant horizons being very uncertain and thus receiving a low weight. Alternatively, one might experiment with shape restrictions on the impulse response functions. It would be interesting to see if restrictions of this type significantly affect our views on what constitutes a reasonable identification of monetary policy shocks.

\section{Conclusion}

This paper asks whether the two propositions of a liquidity effect and long-run monetary neutrality are mutually consistent, within the context of an economically interpretable model of the market for bank reserves and of the Fed's operating regime. The answer appears to be yes, in a robust sense: First, even when we identify our model only up to inequality restrictions, we obtain a reasonable range of values for the liquidity effect. Second, the estimated model does not imply important deviations from long-run neutrality, for a wide range of parameters. Putting the same point another way, imposing long-run neutrality does not tie down the parameter estimates very much within 
the admissible space. The empirical consistency of our estimated model with the widely accepted propositions of long-run neutrality and the liquidity effect increases our confidence in this model as a device for identifying the effects of shocks to monetary policy.

Methodologically, this paper further elaborates on the application of semi-structural VARs by implementing inequality constraints as a means of conditional identification and checking for robustness. Reasonable inequality constraints allow the researcher to study the space of parameters and draw conclusions about the consistency of a set of restrictions imposed in a particular VAR.

Finally, the paper sheds some light on the recent debate about the "vanishing" liquidity effect. We find that in the post-1982 period the magnitude of the liquidity effect is somewhat smaller than in the 19651979 sub-sample, as has been claimed by previous authors. However, we have also shown that results about the magnitude of the liquidity effect may be very dependent on the identification scheme employed. In particular, if we allow for some degree of interest-rate smoothing by the Fed, the best guess is that the liquidity effect has diminished but certainly not disappeared during the $1980^{\prime} \mathrm{s}$. 


\section{Bibliography}

Anderson, L.C. and Jordan, J.L.

(1968) Monetary and Fiscal Actions: A Test of their Relative Importance in Economic Stabilization. Federal Reserve Bank of st.

Louis Review, 50: 11-23.

Andrews, D.W.K.

(1993) Tests for Parameter Instability and Structural Change with Unknown Change Point. Econometrica 61: 821-56.

Bernanke, B. and Blinder, A.

(1992) The Federal Funds Rate and the Channels of Monetary Transmission. American Economic Review, 82: 901-21.

Bernanke, B., Gertler, M. and Watson, M.

(1997) Systematic Monetary Policy and the Effects of Oil Price Shocks. Brookings Papers on Economic Activity, 1: 91-157.

Bernanke, B., and Mihov, I.

(1995) Measuring Monetary Policy. NBER working paper no. 5145, June. Bernanke, B. and Mihov, I.

(forthcoming) Measuring Monetary Policy. Quarterly Journal of Economics.

Blanchard, 0 .

(1989) A Traditional Interpretation of Macroeconomic Fluctuations. American Economic Review, 79: 1146-1164.

Blanchard, 0 . and Quah, D.

(1989) The Dynamic Effects of Aggregate Demand and Supply Disturbances. American Economic Review, 79: 655-673.

Boschen, J., and Mills, L.

(1995) Tests of Long-Run Neutrality Using Permanent Monetary and Real Shocks. Journal of Monetary Economics 35: 25-44. 
Cagan, P.

(1972) The Channels of Monetary Effects on Interest Rates. New York: National Bureau of Economic Research.

Cagan, P., and Gandolfi, A.

(1968) The Lag in Monetary Policy as Implied by the Time Pattern of Monetary Effects on Interest Rates. American Economic Review, Papers and Proceedings 59: 277-284.

Christiano, I.

(1995) Resolving the Liquidity Effect: Comment. Federal Reserve Bank of st. Louis Review 77: 55-62.

Christiano, I., and Eichenbaum, M.

(1992) Identification and the Liquidity Effect of a Monetary Policy Shock. A. Cukierman, Z. Hercowitz, and L. Leiderman, eds., Political Economy, Growth, and Business Cycles, Cambridge MA: MIT Press.

Christiano, L., Eichenbaum, M., and Evans, C.

(1994) Identification and the Effects of Monetary Policy Shocks. Working paper WP-94-7, Federal Reserve Bank of Chicago.

Christiano, L., Eichenbaum, M., and Evans, C.

(1996) The Effects of Monetary Policy Shocks: Evidence from the Elow of Funds. Review of Economics and Statistics, 78: 16-34.

Christiano, L., Eichenbaum, M. and Evans, C.

(forthcoming) Monetary Policy Shocks: What Have We Learned and to what End?" J. Taylor and M. Woodford, eds., Handbook of Macroeconomics, Amsterdam: North-Holland.

Clouse, J.A.

(1994) Recent Developments in Discount Window Policy. Federal Reserve Bulletin 80: $965-77$. 
Cochrane, J.

(1989) The Return of the Liquidity Effect: A Study of the Short-Run Relation Between Money Growth and Interest Rates. Journal of Business and Economic Statistics $7: 75-83$.

Cochrane, J.

(1994) Shocks. A. Meltzer and C. Plosser, eds., Carnegie-Rochester Conference Series on Public Policy, 41, Amsterdam: NorthHolland, 295-364.

Cochrane, J.

(1995) Identifying the Output Effects of Monetary Policy. Unpublished, University of Chicago.

Cornell, B.

(1983) The Money Supply Announcements Puzzle: Review and Interpretation. American Economic Review, 73: 644-57.

Eichenbaum, M.

(1992) Comments on 'Interpreting the Time Series Facts: The Effects of Monetary Policy' by Christopher Sims. European Economic Review 36: 1001-11.

Faust, J., and Leeper, E.

(1995) When Do Long-Run Identifying Restrictions Give Reliable Results? Journal of Business and Economic Statistics, 15: 345-53.

Fisher, M. and Seater, J.

(1993) Long-Run Neutrality and Superneutrality in an ARIMA Framework. American Economic Review, 83: 402-415.

Gali, J.

(1992) How Well Does the IS-LM Model Fit Postwar U.S. Data? Quarterly Journal of Economics, 107: 709-38. 
Geweke, J.

(1986) The Superneutrality of Money in the United States: An Interpretation of the' Evidence. Econometrica, 54: 1-21.

Gibson, W. E.

(1968) The Iag in the Effect of Monetary Policy on Income and Interest Rates. Quarterly Journal of Economics, 85: 288-300.

Goodfriend, M.

(1983) Discount Window Borrowing, Monetary Policy, and the PostOctober 6, 1979 Federal Reserve Operating Procedure. Journal of Monetary Economics, 12: 343-56.

Gordon, D.B. and Leeper, E.M.

(1994) The Dynamic Impacts of Monetary Policy: An Exercise in Tentative Identification. Journal of Political Economy, 102: $1228-57$

King, R., and Watson, M.

(1997) Testing Long-Run Neutrality. Federal Reserve Bank of Richmond Economic Quarterly, 83:, 69-101.

Lastrapes, W. and Selgin, G.

(1995) The Liquidity Effect: Identifying Short-Run Interest Rate Dynamics Using Long-Run Restrictions. Journal of Macroeconomics, 17: 387-404.

Leeper, E.M., and Gordon, D.B.

(1992) In Search of the Liquidity Effect. Journal of Monetary Economics 29: 341-369.

Leeper, E.M., Sims, C., and zha, T.

(1997) What Does Monetary Policy Do? Brookings Papers on Economic Activity, 2: 1-63. 
Lucas, R.E., Jr.

(1972) Econometric Testing of the Natural Rate Hypothesis.

o. Eckstein, ed., The'Econometrics of Price Determination, Washington: Board of Governors of the Federal Reserve System.

Lucas, R.E., Jr.

(1976) Econometric Policy Evaluation: A Critique. K. Brunner and A.Meltzer, eds., Carnegie-Rochester Conference Series on Public Policy 1, 19-46.

Mccallum, B.

(1984) On Low Frequency Estimates of Long-Run Relationships in Macroeconomics. Journal of Monetary Economics, 14: 3-14.

Melvin, $M$.

(1983) The Vanishing Liquidity Effect of Money on Interest: Analysis and Implications for Policy. Economic Inquiry 21: 188-202.

Mishkin, E.S.

(1982) Monetary Policy and Short-Term Interest Rates: An Efficient Markets-Rational Expectations Approach. Journal of Finance, $63-72$

Mishkin, E.S.

(1983) A Rational Expectations Approach to Macroeconomics: Testing Policy Ineffectiveness and Efficient-Markets Models, Chicago: University of Chicago Press.

Pagan, A., and Robertson, J.

(1995) Resolving the Liquidity Effect. Federal Reserve Bank of st. Louis Review, 77: 33-54.

Peristiani, S.

(1991) The Model structure of Discount Window Borrowing. Journal of Money, Credit, and Banking, 23: 13-34. 
Quandt, R.E.

(1960) Tests of the Hypothesis that a Iinear Regression System Obeys Two Separate Regimes. Journal of American Statistical Association 55: $324-330$.

Reichenstein, $w$.

(1987) The Impact of Money on Short-term Interest Rates. Economic Inquiry, 25: 67-82.

Romer, C.D., and Romer, D.H.

(1989) Does Monetary Policy Matter? A New Test in the Spirit of Friedman and Schwartz. NBER Macroeconomics Annual 4: 121-70.

Romer, C.D., and Romer, D.H.

(1994) Monetary Policy Matters. Journal of Monetary Economics, $34: 75-88$

Rotemberg, J., Driscoll, J., and Poterba, J.

(1995) Money, Output, and Prices: Evidence from a New Monetary Aggregate. Journal of Business and Economic Statistics, 13: $67-84$

Rudebusch, G.

(1997) Do Measures of Monetary Policy in a VAR Make Sense? Unpublished, Federal Reserve Bank of San Francisco. Sargent, $T$.

(1971) A Note on the 'Accelerationist' Controversy. Journal of Money, Credit, and Banking, 3: 721-725.

Sarte, P.-D.

(1997) On the Identification of structural Vector Autoregressions. Federal Reserve Bank of Richmond Economic Quarterly, 83: $45-67$.

Sims, C.A.

(1980) Comparison of Interwar and Postwar Business Cycles: Monetarism 
Reconsidered. American Economic Review, Papers and Proceedings, $70: 250-57$

Sims, C.A.

(1986) Are Forecasting Models Usable for Policy Analysis? Federal Reserve Bank of Minneapolis Quarterly Review, 2-16.

Sims, C.A.

(1992) Interpreting the Macroeconomic Time Series Facts: The Effects of Monetary Policy. European Economic Review, 36: 975-1011.

Sims, C.A. and Zha, T.

(1995) Does Monetary Policy Generate Recessions? Using Less Aggregated Price Data to Identify Monetary Policy. Unpublished. Yale University.

Stock, J. and Watson, M.

(1995) Evidence on Structural Instability in Macroeconomic Time Series Relations. Unpublished. Princeton University.

strongin, s.

(1995) The Identification of Monetary Policy Disturbances: Explaining the Liquidity Puzzle. Journal of Monetary Economics, 35: 463-97. Tinsley, P., Farr, H., Fries, G., Garrett, B. and von zur Muehlen, P. (1982) Policy Robustness: Specification and Simulation of a Monthly Money Market Model. Journal of Money, Credit, and Banking, 14 $($ part 2): $829-56$ 


\section{ENDNOTES}

1 We defer for the moment the question of whether these changes are anticipated or unanticipated.

${ }^{2}$ See Geweke (1986), Boschen and Mills (1995), and Rotemberg, Driscoll, and Poterba (1995) for related analyses.

3 Leeper and Gordon (1992) and King and Watson (1997) stress the problems created by endogeneity of the money stock.

4 See Bernanke and Blinder (1992), Sims (1992), Christiano and Eichenbaum (1992), Christiano, Eichenbaum, and Evans $(1994,1996)$, and Strongin (1995), among others.

${ }^{5}$ Monthly data for real GDP and the GDP deflator are developed by state space methods using available monthly indicator variables and allowing for serially correlated interpolation error. For a detailed data description see Bernanke and Mihov (forthcoming) and Bernanke, Gertler, and Watson (1997).

6 This section draws heavily on Bernanke and Mihov (forthcoming), to which the reader is referred for additional details and motivation.

7 Christopher sims has criticized this assumption on several occasions. We do agree that it is implausible on a priori grounds that the commodity prices do not react to monetary policy shocks contemporaneously; and we have explored the implications of this assumption in background work for Bernanke and Mihov (forthcoming). In our context, allowing for contemporaneous effects of policy shocks on the index of commodity prices does not alter the estimates of the structural parameters or the shapes of the impulse responses significantly, and so for simplicity we maintain the block-orthogonality assumption.

8 Bernanke and Mihov (forthcoming) discuss conditions under which this assumption is reasonable. In an earlier version of that paper, Bernanke 
and Mihov (1995) estimate a variant of the model with the discount rate and find that including the discount rate has little effect on their principal results.

9 A strong finding of Bernanke and Mihov (forthcoming) is that the nonborrowed-reserves measure is a poor indicator of monetary policy, except during the 1979-82 period in which the Fed explicitly employed a nonborrowed-reserves targeting procedure. Christiano, Eichenbaum, and Evans (forthcoming) question this result, contending that the model (5)(7) is misspecified. In particular, they argue for including the innovation to nonborrowed reserves as an additional variable in the borrowing equation, (6), so that the model which imposes nonborrowedreserves targeting is no longer over-identified land thus no longer vulnerable to rejection). CEE base this proposed modification on Goodfriend (1983), who pointed out that (because high borrowing from the window today may reduce access in the future) banks should worry about expected future values as well as current values of the funds ratediscount rate spread when borrowing. Thus, CEE advocate inclusion of nonborrowed reserves in the borrowing function because, in principle, the innovation to nonborrowed reserves could contain information about future values of this spread.

The CEE point is indeed correct in principle, but as far as we are aware there is little empirical justification for their claim that nonborrowed reserves should be in the borrowing function. In particular, CEE do not show that the innovation in nonborrowed reserves provides important marginal information about future values of the funds rate, or that the freely-estimated coefficient on this variable is consistent with either its information content or banks' optimal response to that information. Indeed, specifications in the form of our equation (6), excluding nonborrowed reserves, are universally maintained 
in the modern literature: For example, Goodfriend (1983) himself specializes his model so that it is precisely of the form of $(6)$; the point of his paper is not that additional variables should be added to the borrowing function, but that the slope of the borrowing function may depend on the operating regime, a possibility that is fully accomodated in the Bernanke-Mihov framework. Borrowing equations of the form of (6) are also standard in the Fed's monthly model of the reserves market (Tinsley et al., 1982) and in other applied monetary models, reflecting the close empirical relationship of borrowings and the spread (Peristiani, 1991; Clouse, 1994). The main exception to the observation that borrowings and the spread are highly correlated is the sharp drop in borrowings in the second half of the 1980s, which appears to reflect reluctance of banks to signal financial weakness to the market (clouse, 1994), not dynamic concerns of the type raised by Goodfriend (1983). There is additional, indirect evidence for our specification, which is that our estimates are strongly consistent with conventional understandings of when and how the Fed has changed its operating procedure. It is surprising that CEE would advocate the use of nonborrowed reserves as a policy indicator for the whole post-1965 period, when there is widespread agreement among economists that the Fed has smoothed interest rates at least during some sub-periods. The practice of interest-rate smoothing invalidates NBR as a policy indicator in general. We present additional reasons to be concerned about the use of nonborrowed reserves as a policy indicator below. ${ }^{10}$ Figures III and IV are based on the full-sample estimates shown in Table II. As we have noted, this is technically illegitimate because of the breaks in the covariance matrix. However, as Table II shows, the estimates for the full sample are qualitatively similar to those for the interest-rate-smoothing regimes prior to 1979 and after 1982; and the 
implied impulse responses for the full-sample and sub-sample estimates are also quite similar. Thus, to avoid showing results for each subsample separately, we present only full-sample results here. Below, when we apply the inequality constraints for identification, we discuss in more detail the differences between sub-periods. ${ }^{11}$ As our discussant Jordi Gali explains in more detail, if there are unit roots in the variables of our system, our decision to run the first-stage VAR in levels creates the possibility of downward bias in the estimated long-run response of output. However, we cannot be sure that there are unit roots in our system (although the series are highly persistent, the eigenvalues of the companion matrix are always less than one in modulus). By running the first-stage VAR in levels we insure consistency of the reduced-form parameters (and hence the impulse responses) whether there are unit roots in the system or not (indeed, if there are unit roots, the estimates are super-consistent). One might attempt to correct for possible bias through bootstrapping techniques, but unfortunately bootstrapping techniques for non-stationary or nearly non-stationary time series are not well-developed at this juncture. 12 Again results are based on estimates from the full sample, with the caveat noted above about the instability of the covariance matrix. Subsample results are given later in the paper.

${ }^{13}$ Actually, the only model whose vector of parameters can be located precisely on this picture is Bernanke-Mihov, since this is the only just-identified model. All other models are overidentified, and therefore the statements in this paragraph should be qualified that these models approximate a specific root, and that the actual values of parameter estimates need not lie on the manifold of admissible parameters described in this section. 
14 In the post-1982 results, although not for those from 1965-1979, we are again averaging over different operating regimes, as indicated by the breaks in the covariance matrix of residuals. It is interesting that for the post-1988 period (not shown), in which there are no breaks, there is some evidence that the liquidity effect has again strengthened. 15 Gali (1992) uses a combination of short-run and long-run identifying restrictions. For another attempt to use long-run restrictions to identify monetary policy shocks, see Lastrapes and Selgin (1995). 
TABLE I

Contribution of Money Shocks to the Variance Decomposition of the Forecast Errors of Output from Bivariate Quarterly VARs of Money and Output

(1966:1 - 1996:4)

\begin{tabular}{rrrr}
\hline & \multicolumn{3}{c}{ Measures of Money } \\
\cline { 2 - 4 } Horizon & M2 & M1 & MB \\
\hline & & & \\
1 quarter & 0.11 & 3.46 & 2.01 \\
1 year & 6.44 & 16.03 & 7.73 \\
2 years & 12.24 & 28.77 & 12.79 \\
3 years & 18.36 & 43.88 & 19.02 \\
5 years & 31.46 & 66.52 & 29.95 \\
7 years & 41.80 & 76.00 & 37.96 \\
10 years & 48.56 & 80.43 & 46.44 \\
\hline
\end{tabular}


TABLE II

Parameter Estimates from the Just-identified Model (Monthly)

\begin{tabular}{cccc}
\hline Sample & $\beta$ & $\phi^{\mathrm{d}}$ & $\phi^{\mathrm{b}}$ \\
& & & \\
$1965: 1$ & $0.023(0.005)$ & $0.701(0.063)$ & $-0.438(0.202)$ \\
- & & & \\
$1996: 12$ & & & \\
& & & \\
$1965: 1$ & $0.019(0.009)$ & $0.795(0.093)$ & $-0.822(0.251)$ \\
- & & & \\
$1979: 9$ & & & \\
$1979: 10$ & $0.015(0.005)$ & $0.245(0.333)$ & $-0.468(0.599)$ \\
- & & & \\
$1982: 9$ & & & \\
$1982: 10$ & $0.046(0.021)$ & $0.731(0.061)$ & $-0.198(0.249)$ \\
- & & & \\
$1996: 12$ & & & \\
$1988: 3$ & $0.052(0.026)$ & $0.676(0.055)$ & $-0.053(0.130)$ \\
- & & & \\
$1996: 12$ & & & \\
\hline
\end{tabular}

The estimates are from a seven-variable monthly VAR (see text for explanations). The structural model is exactly identified by the assumption $\alpha=0$. The figures in the parentheses are standard errors. 
TABLE III

Parameter Estimates from the Overidentified Model with Long-Run Restrictions (Monthly)

\begin{tabular}{|c|c|c|c|c|c|c|c|}
\hline Sample & $\begin{array}{c}\text { Restrictions } \\
\text { on } \alpha \\
\end{array}$ & $\alpha$ & $\beta$ & $\phi^{d}$ & $\phi^{b}$ & $\begin{array}{c}\text { Liquidity } \\
\text { Effect }\end{array}$ & $\begin{array}{c}\text { Tests for } \\
\text { OIR }\end{array}$ \\
\hline $\begin{array}{c}1965: 1 \\
- \\
1996: 12\end{array}$ & $\begin{array}{c}\text { Unrestricted } \\
\alpha>0\end{array}$ & $\begin{array}{r}-0.001(0.002) \\
0.000(0.001)\end{array}$ & $\begin{array}{l}0.030(0.005) \\
0.025(0.003)\end{array}$ & $\begin{array}{l}0.775(0.111) \\
0.740(0.068)\end{array}$ & $\begin{array}{l}-0.252(0.414) \\
-0.388(0.494)\end{array}$ & $\begin{array}{l}34.94 \\
40.22\end{array}$ & $\begin{array}{l}0.999 \\
0.858\end{array}$ \\
\hline $\begin{array}{c}1965: 1 \\
- \\
1979: 9\end{array}$ & $\begin{array}{c}\text { Unrestricted } \\
\alpha>0\end{array}$ & $\begin{array}{r}-0.002(0.002) \\
0.000(0.002)\end{array}$ & $\begin{array}{ll}0.021 & (0.006) \\
0.018 & (0.006)\end{array}$ & $\begin{array}{l}0.838(0.099) \\
0.772(0.089)\end{array}$ & $\begin{array}{l}-0.768(0.532) \\
-0.852(0.476)\end{array}$ & $\begin{array}{l}52.97 \\
56.80\end{array}$ & $\begin{array}{l}0.999 \\
0.951\end{array}$ \\
\hline $\begin{array}{c}1982: 10 \\
- \\
1996: 12\end{array}$ & $\begin{array}{l}\text { Unrestricted } \\
\qquad \alpha>0\end{array}$ & $\begin{array}{l}0.007(0.075) \\
0.007(0.075)\end{array}$ & $\begin{array}{ll}0.029 & (0.053) \\
0.029 & (0.053)\end{array}$ & $\begin{array}{l}0.642(0.682) \\
0.642(0.682)\end{array}$ & $\begin{array}{l}-0.388(1.249) \\
-0.388(1.249)\end{array}$ & $\begin{array}{l}27.82 \\
27.82\end{array}$ & $\begin{array}{l}0.999 \\
0.999\end{array}$ \\
\hline $\begin{array}{c}1988: 3 \\
- \\
1996: 12\end{array}$ & $\begin{array}{c}\text { Unrestricted } \\
\alpha>0\end{array}$ & $\begin{array}{l}0.002(0.018) \\
0.002(0.018)\end{array}$ & $\begin{array}{l}0.109(0.864) \\
0.109(0.864)\end{array}$ & $\begin{array}{l}0.815(0.080) \\
0.815(0.080)\end{array}$ & $\begin{array}{l}0.047(0.153) \\
0.047(0.153)\end{array}$ & $\begin{array}{l}9.000 \\
9.000\end{array}$ & $\begin{array}{l}0.999 \\
0.999\end{array}$ \\
\hline
\end{tabular}

The estimates are from a seven-variable monthly VAR (see text for explanations). The last column presents p-values from tests of overidentifying restrictions based on the minimized value of the criterion function. The figures in the brackets are standard errors. The two long-run restrictions which overidentify the model are: (1) no long run effect of money supply shocks on real output and (2) no long-run effect of money supply shocks on real balances. 

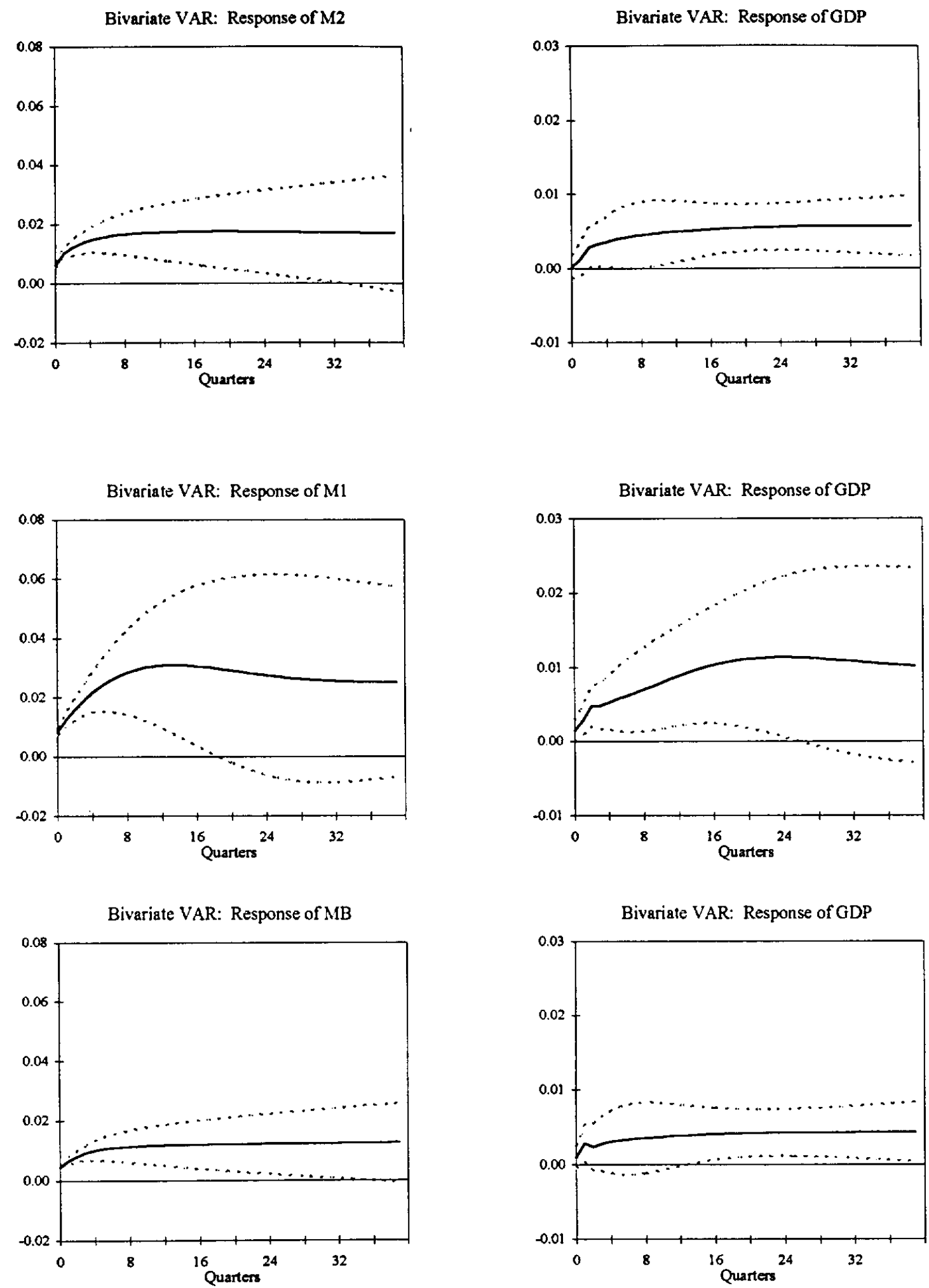

FIGURE I

Responses of Output and Monetary Aggregates to Money Supply Shocks from Bivariate Quarterly VARs (1966:1 - 1996:4) 

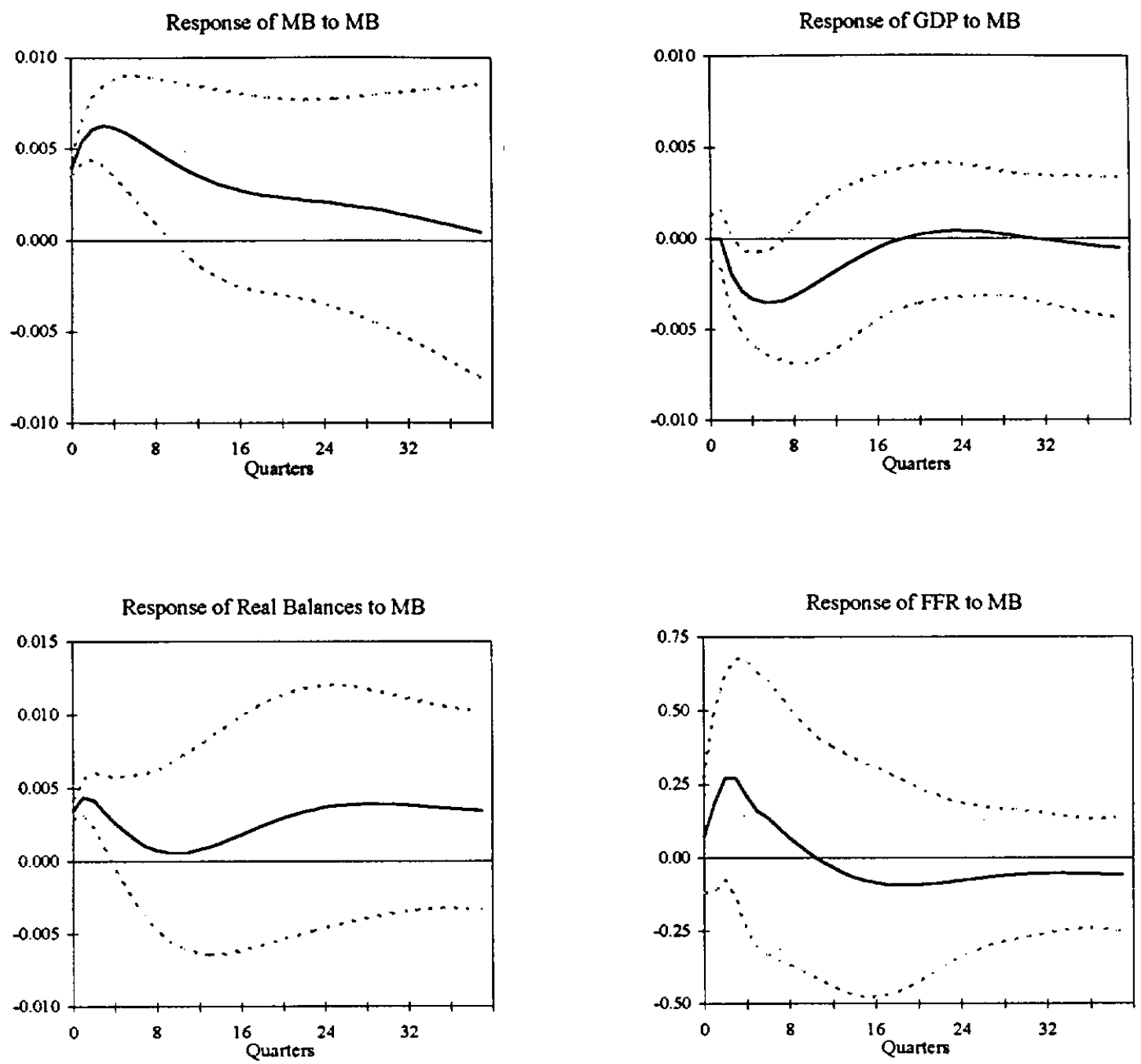

FIGURE II (a)

Impulse Responses from Quarterly VARs with Monetary Base, GDP, Real Balances, and the Federal Funds Rate (1966:1 - 1996:4) 

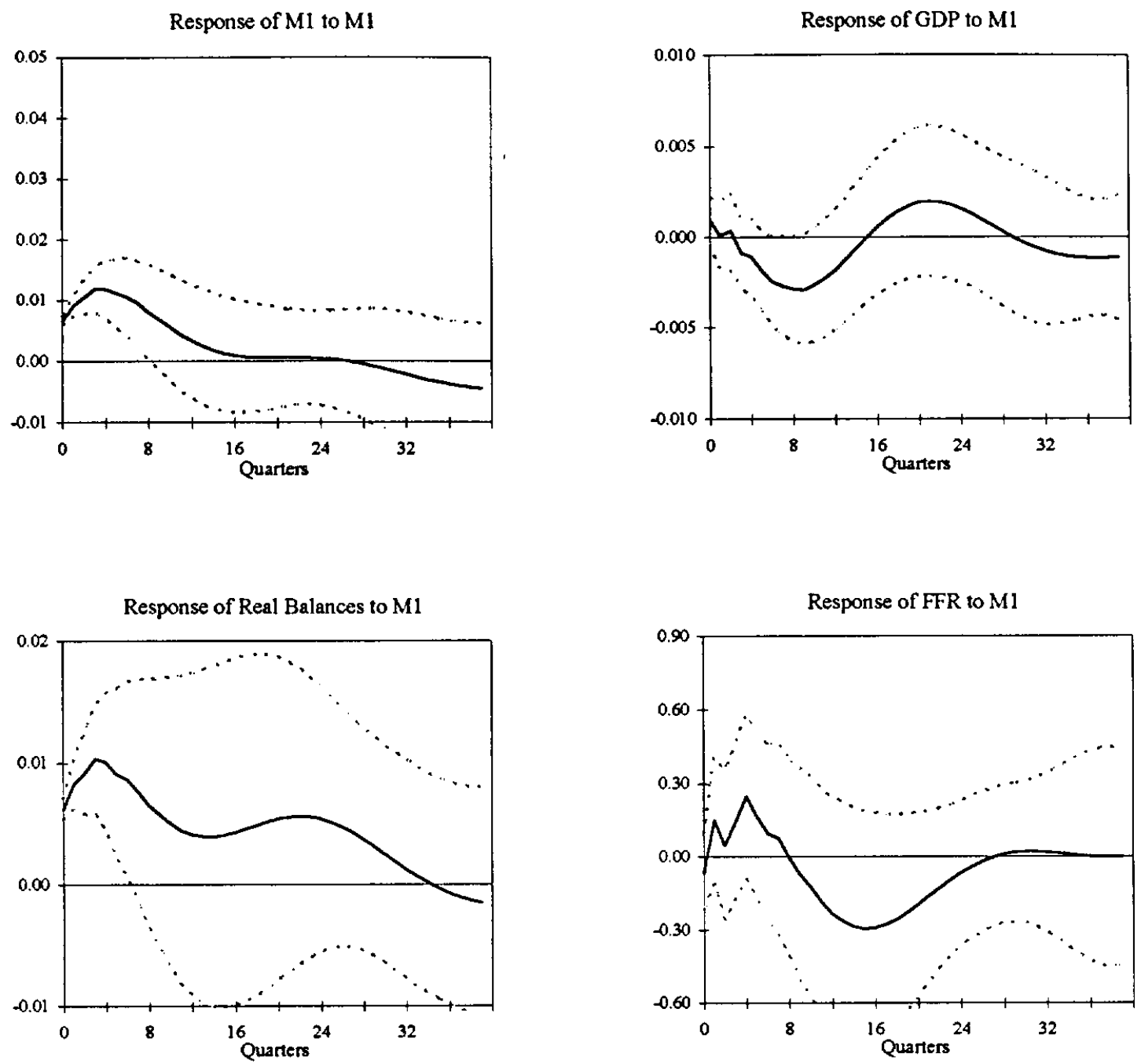

FIGURE II (b)

Impulse Responses from Quarterly VARs with M1, GDP, Real Balances, and the Federal Funds Rate (1966:1 - 1996:4) 

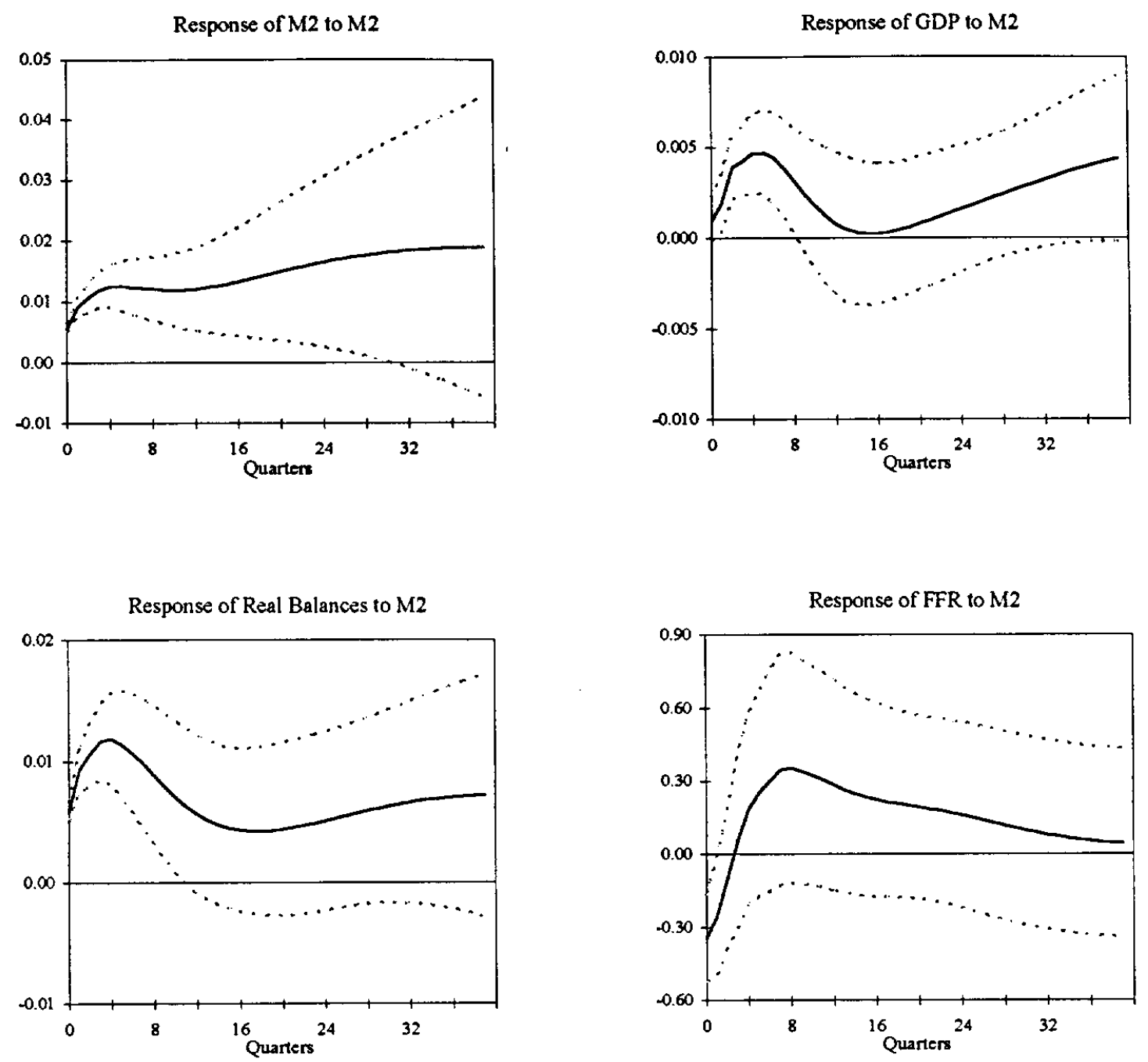

FIGURE II (c)

Impulse Responses from Quarterly VARs with M2, GDP, Real Balances, and the Federal Funds Rate (1966:1 - 1996:4) 

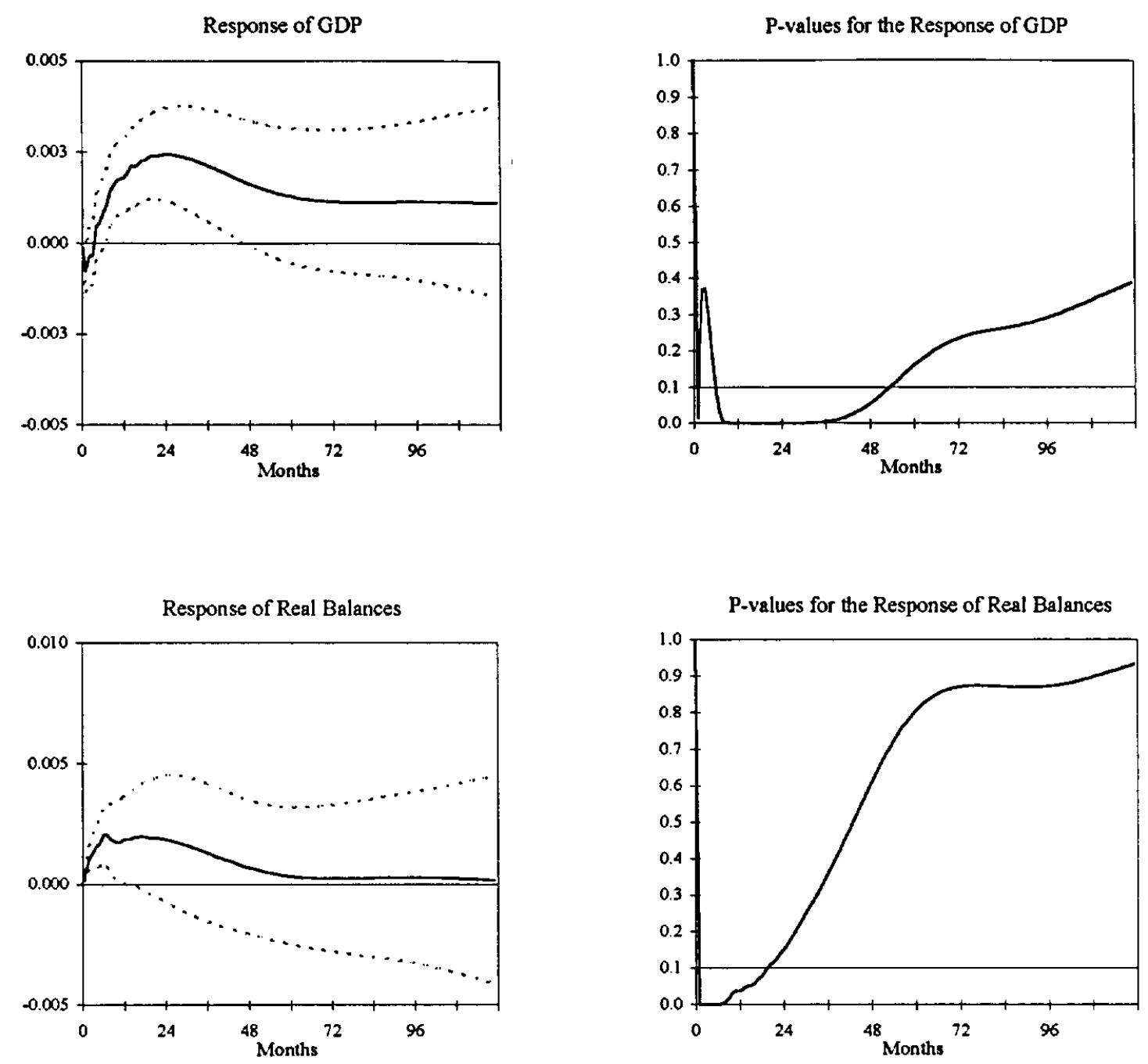

FIGURE III

Impulse Responses from a Seven-Variable VAR with GDP, GDP Deflator, Commodity Price Index, M2, Total Reserves, Nonborrowed Reserves and the Federal Funds Rate (1966:1 - 1996:12) 
Response of FFR

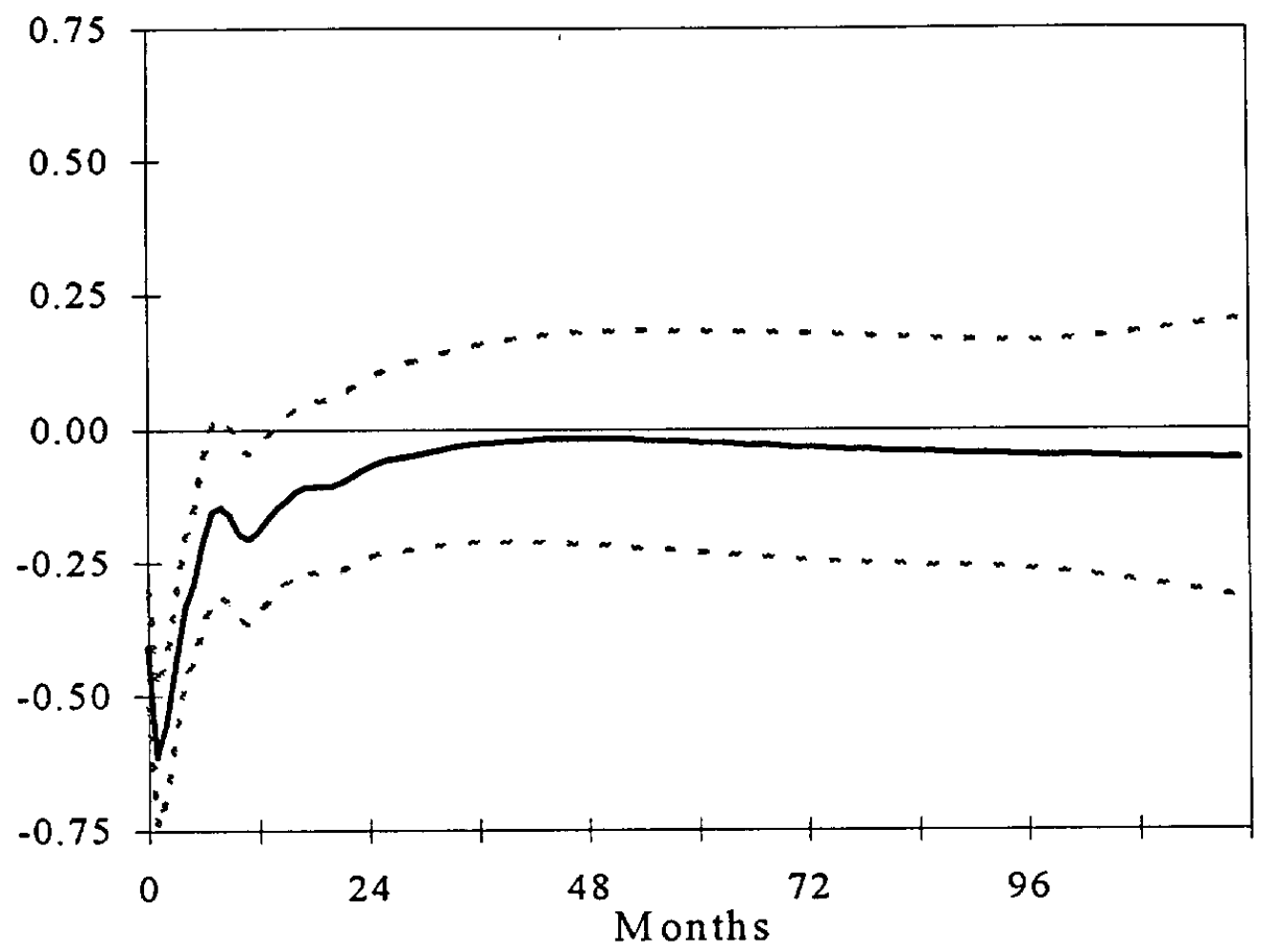

FIGURE IV

Impulse Response of the Federal Funds Rate from a Seven-Variable VAR with GDP, GDP Deflator, Commodity Price Index, M2, Total Reserves, Nonborrowed Reserves and the Federal Funds Rate (1966:2 - 1996:12) 

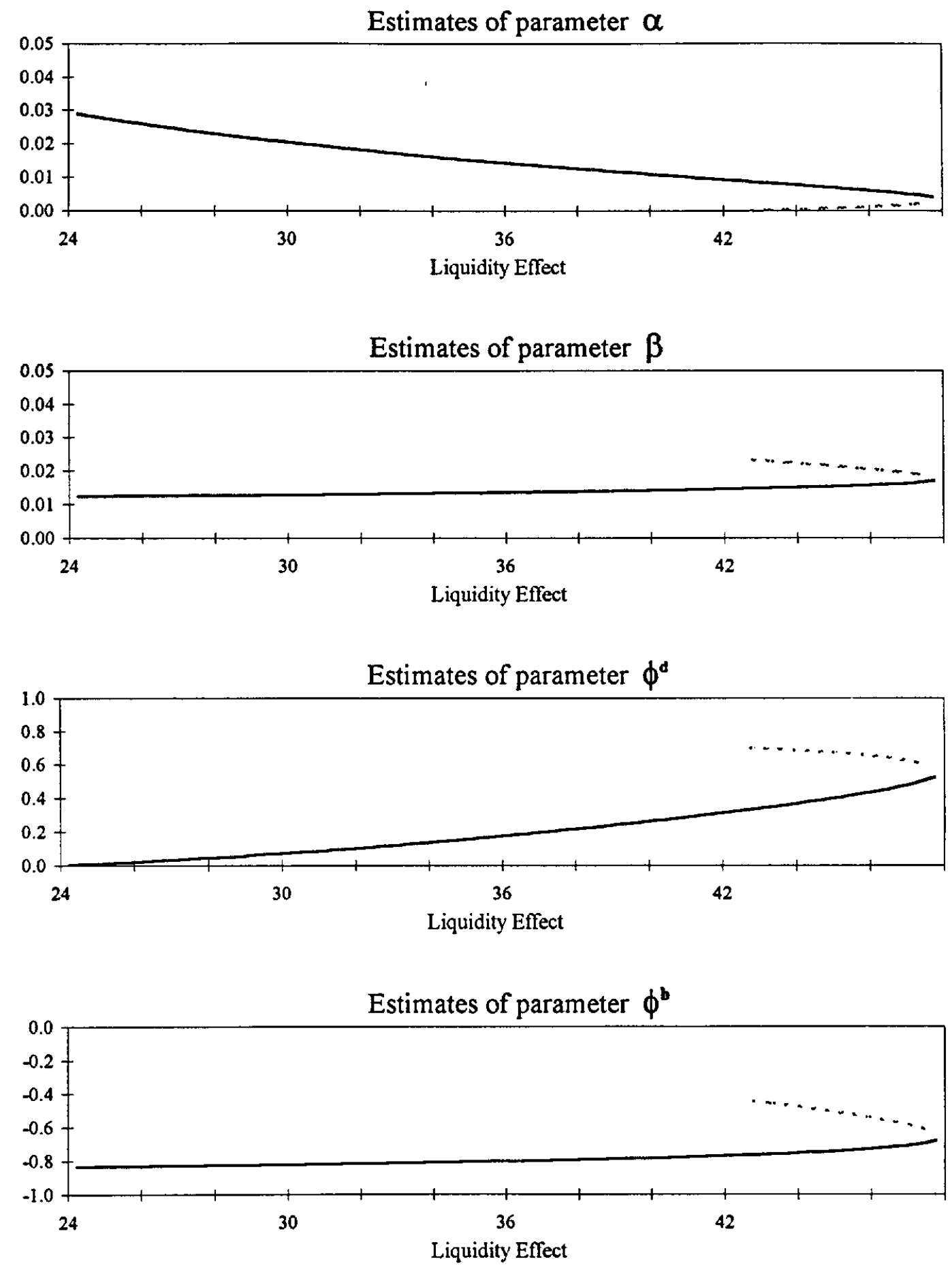

FIGURE V

The Space of Admissible Structural Parameters (1966:1 - 1996:12) 
GDP Response After One Year

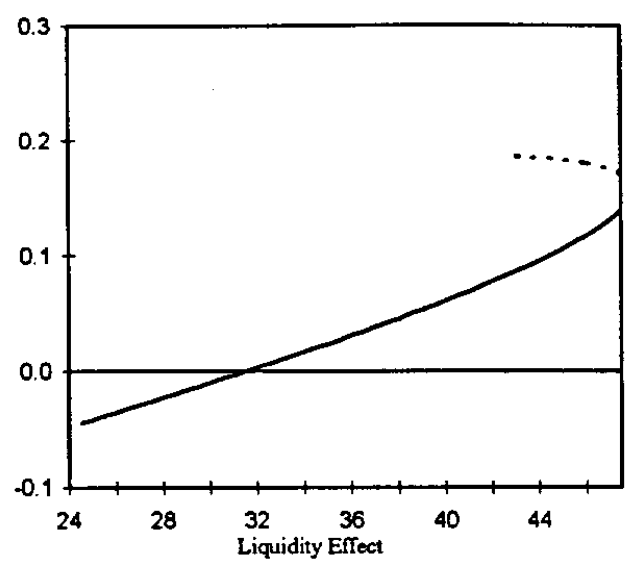

GDP Response After Two Years

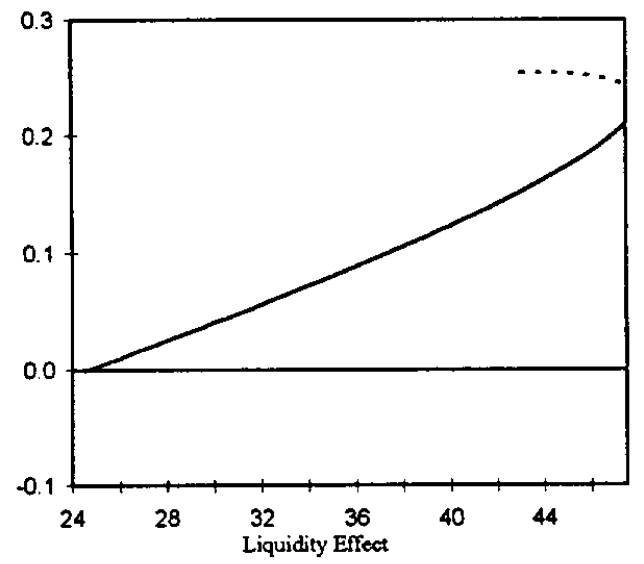

GDP Response After Three Years

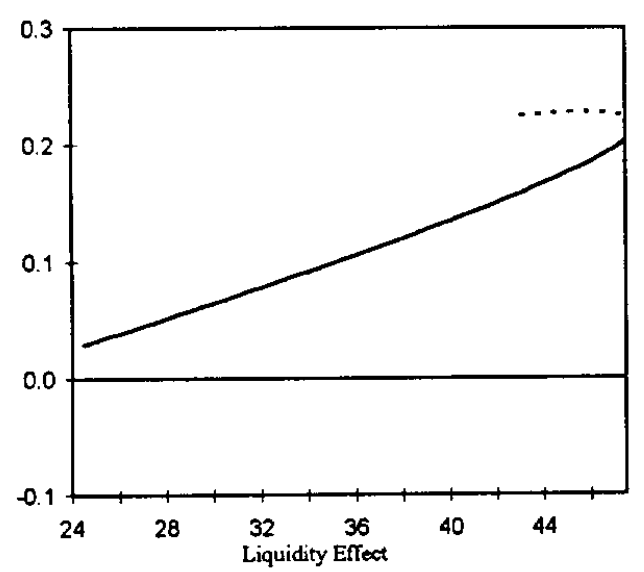

P-value for the GDP Response After One Year

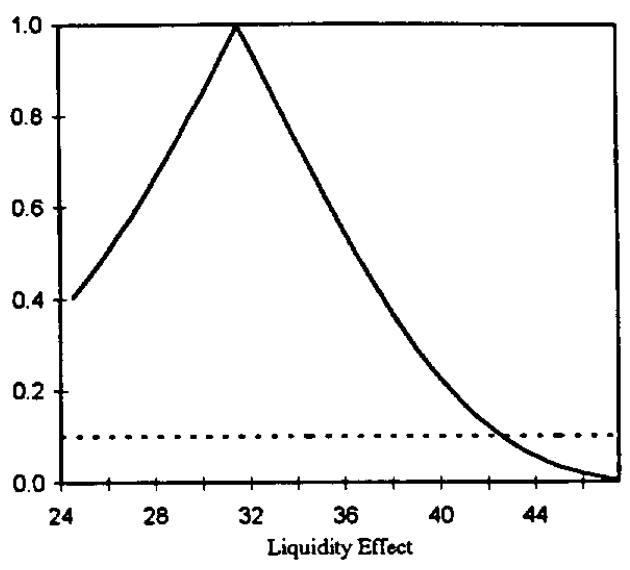

P-value for the GDP Response After Two Years

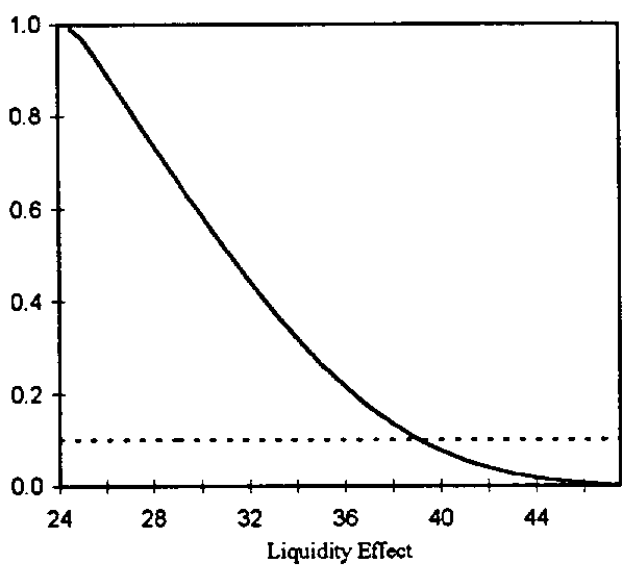

P-value for the GDP Response After Three Years

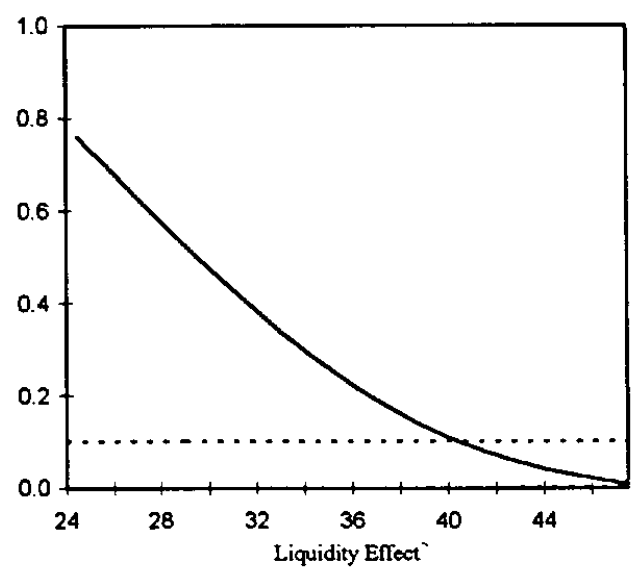

FIGURE VI(a)

Responses of Output to Money Supply Shocks for Different Values of the Liquidity Effect (1966:1 - 1996:12) 


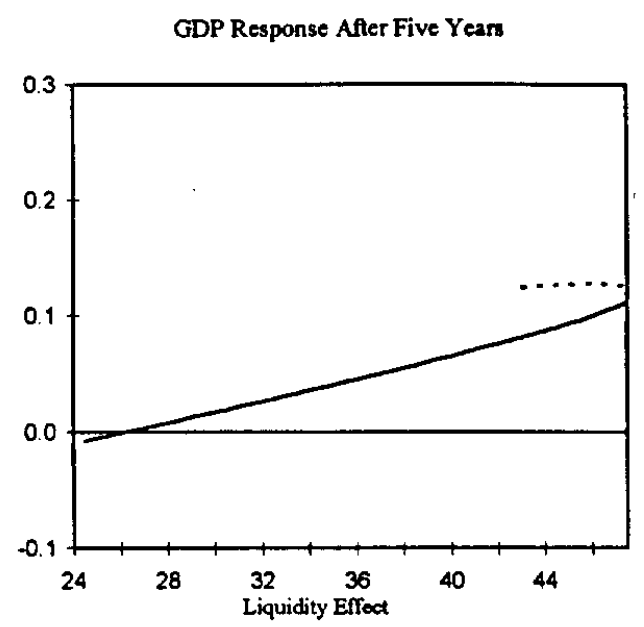

P-value for the GDP Response After Five Years

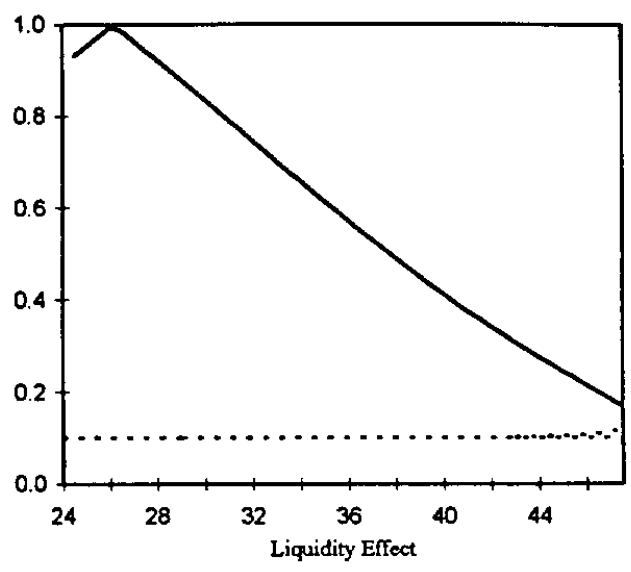

GDP Response After Seven Years

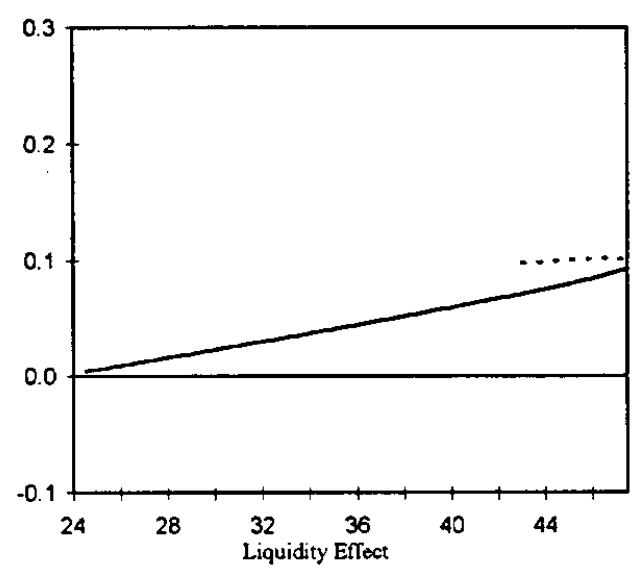

P-value for the GDP Response After Seven Years

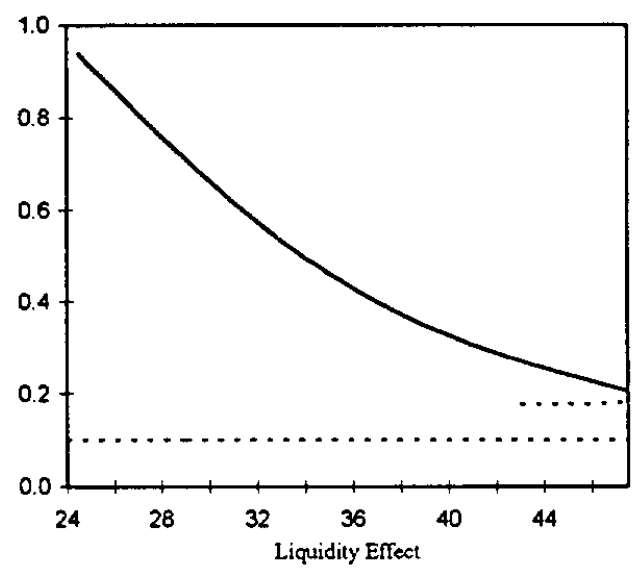

GDP Response After Ten Years

P-value for the GDP Response After Ten Years
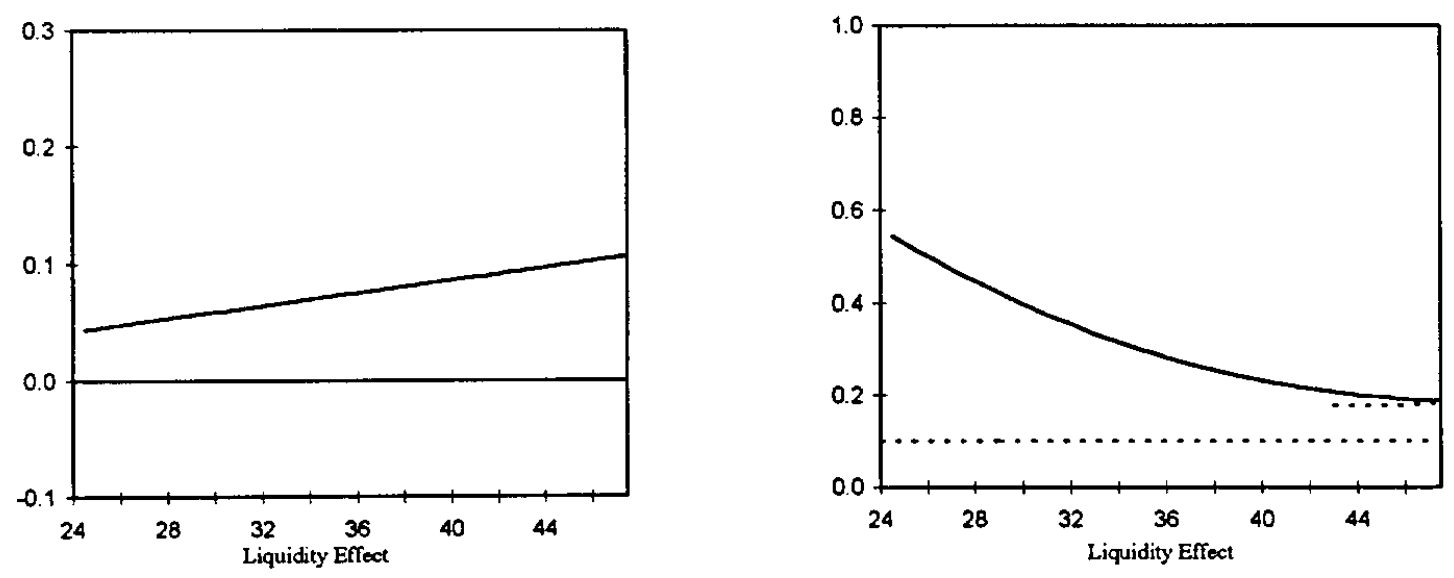

FIGURE VI(b)

Responses of Output to Money Supply Shocks for Different Values of the Liquidity Effect (1966:1 - 1996:12) 

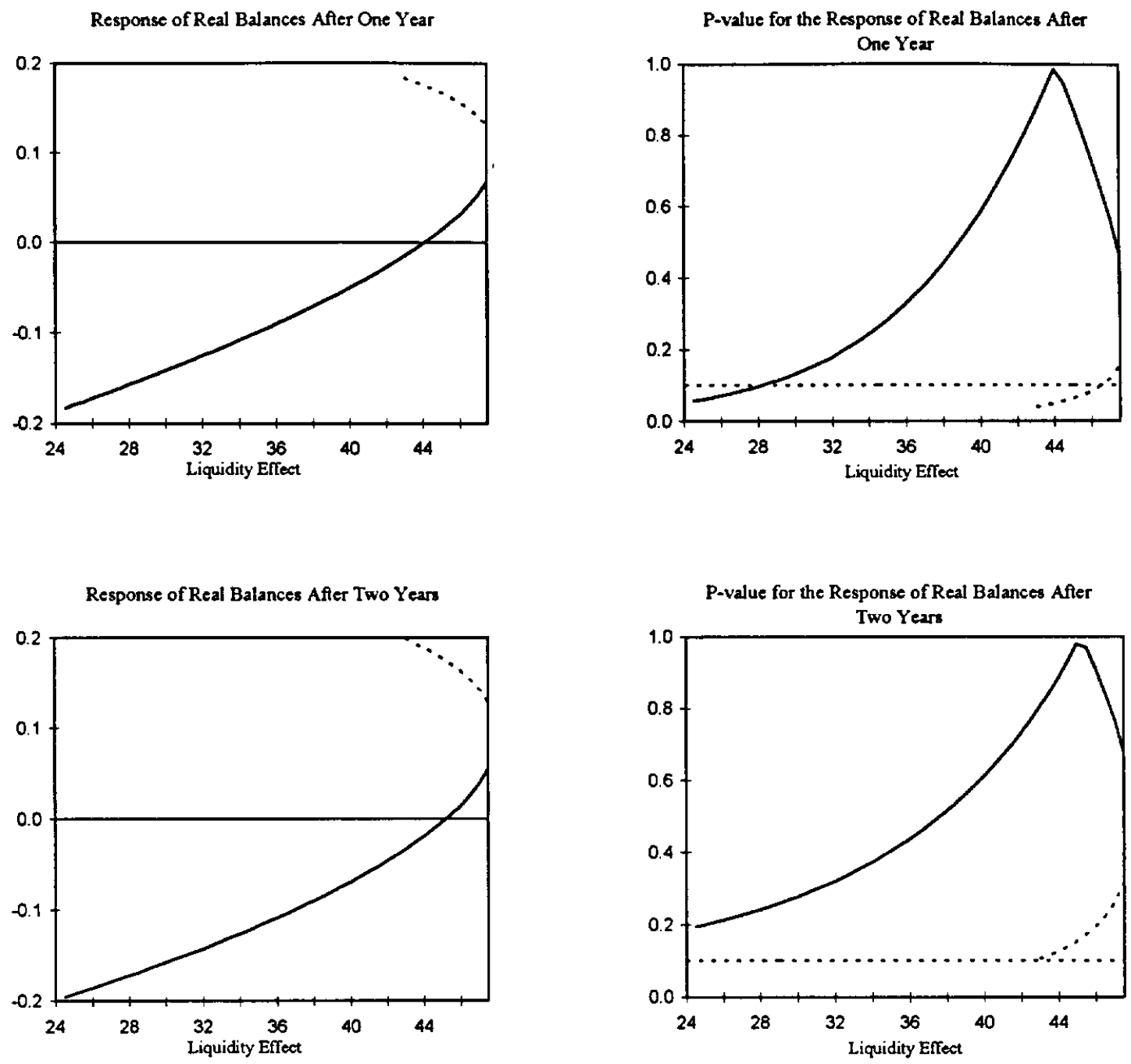

Response of Real Balances After Three Years
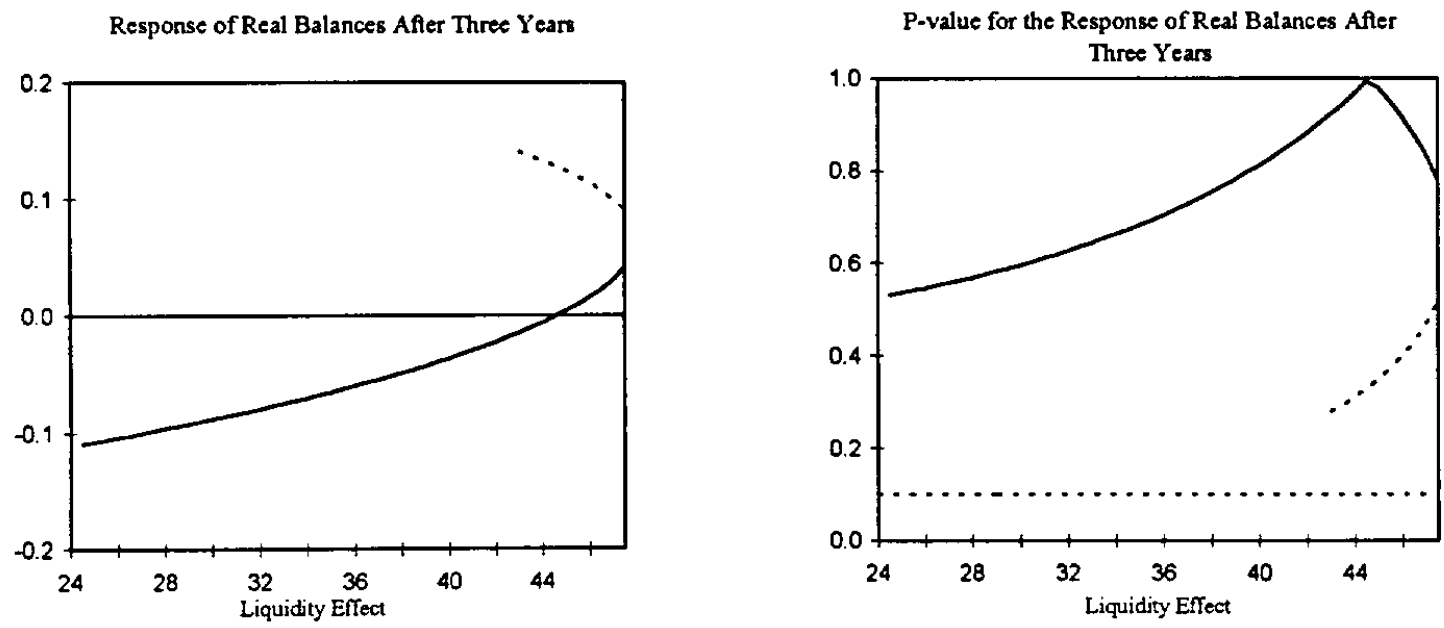

FIGURE VII(a)

Responses of Real Balances to Money Supply Shocks for Different Values of the Liquidity Effect (1966:1 - 1996:12) 
Response of Real Balances After Five Yean

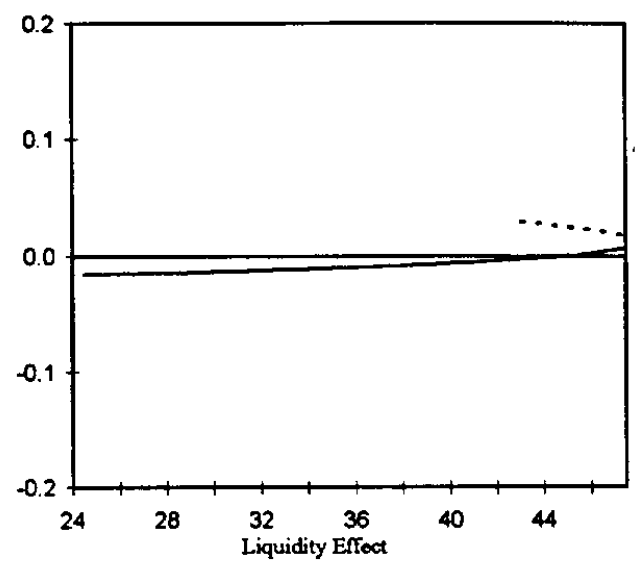

Response of Real Balances After Seven Years

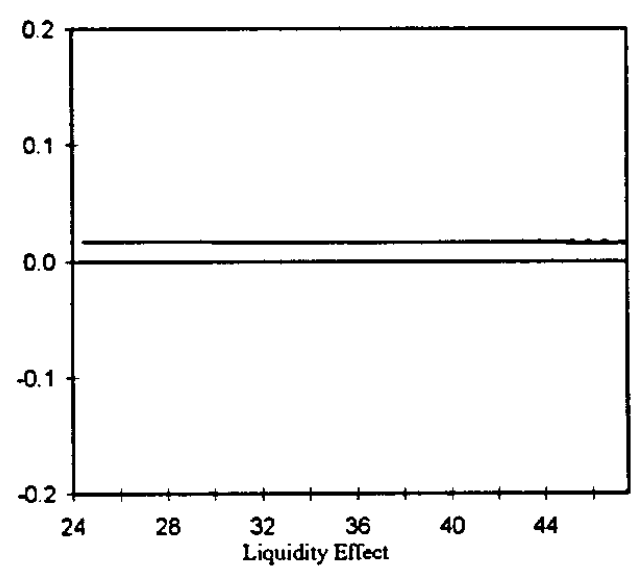

Response of Real Balances After Ten Years

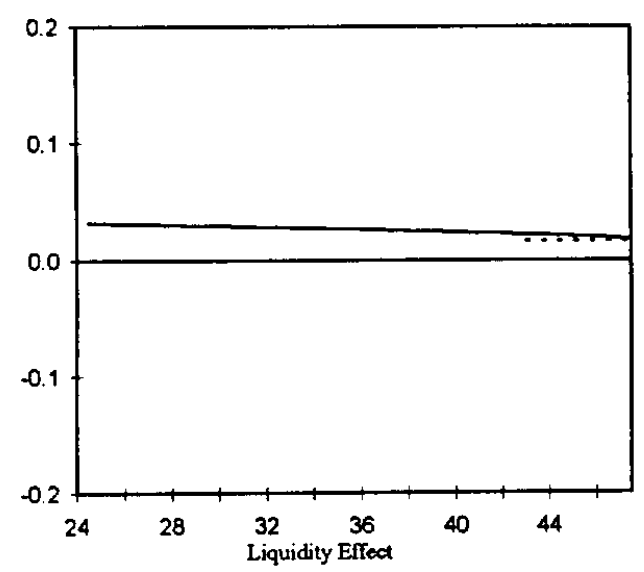

P-value for the Response of Real Balances After Five Years

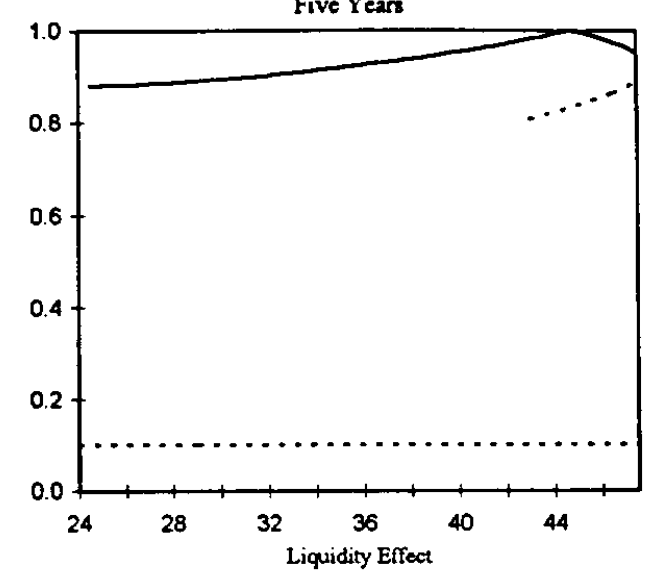

P-value for the Response of Real Balances After Seven Years

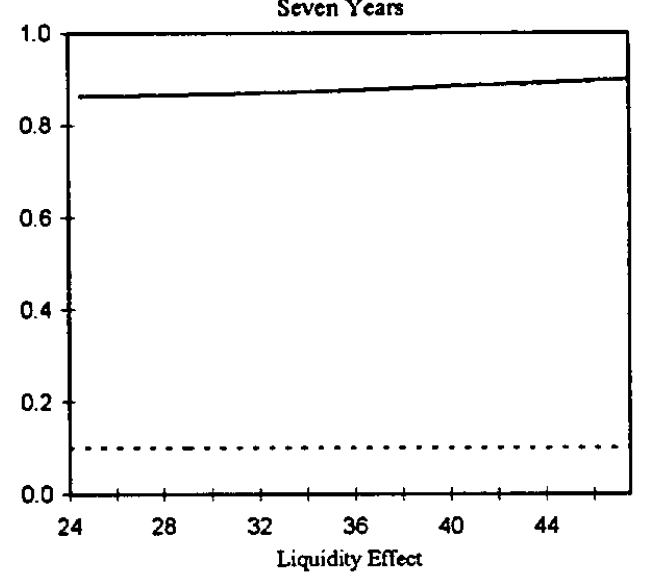

P-value for the Response of Real Balances After Ten Years

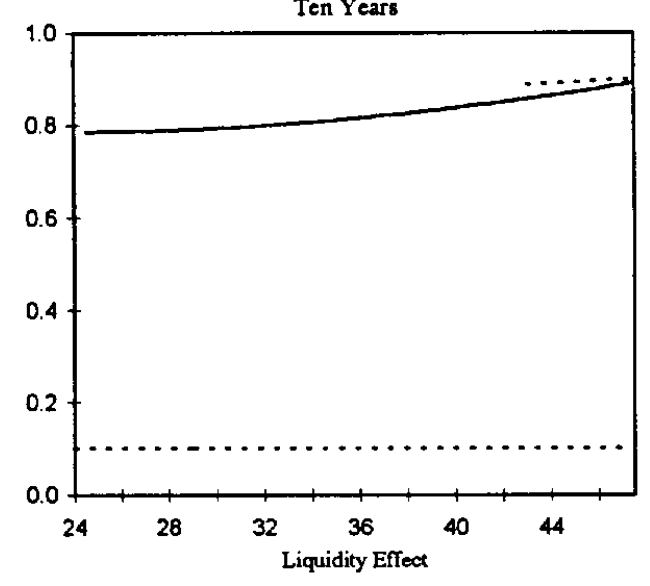

FIGURE VII(b)

Responses of Real Balances to Money Supply Shocks for Different Values of the Liquidity Effect (1966:1 - 1996:12) 

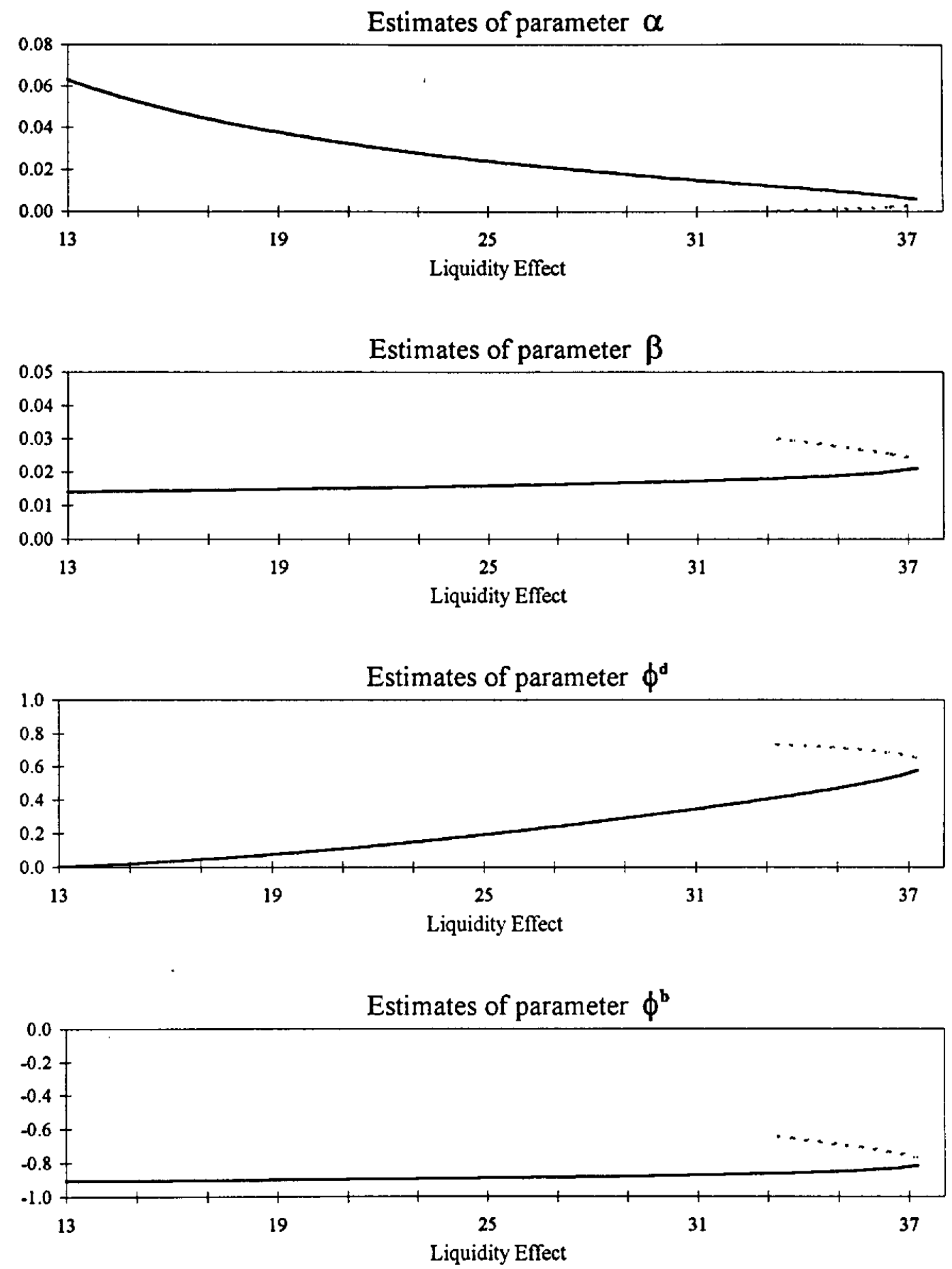

FIGURE VIII (a)

The Space of Admissible Structural Parameters (1966:1 - 1979:9)

(partial-sample residuals) 

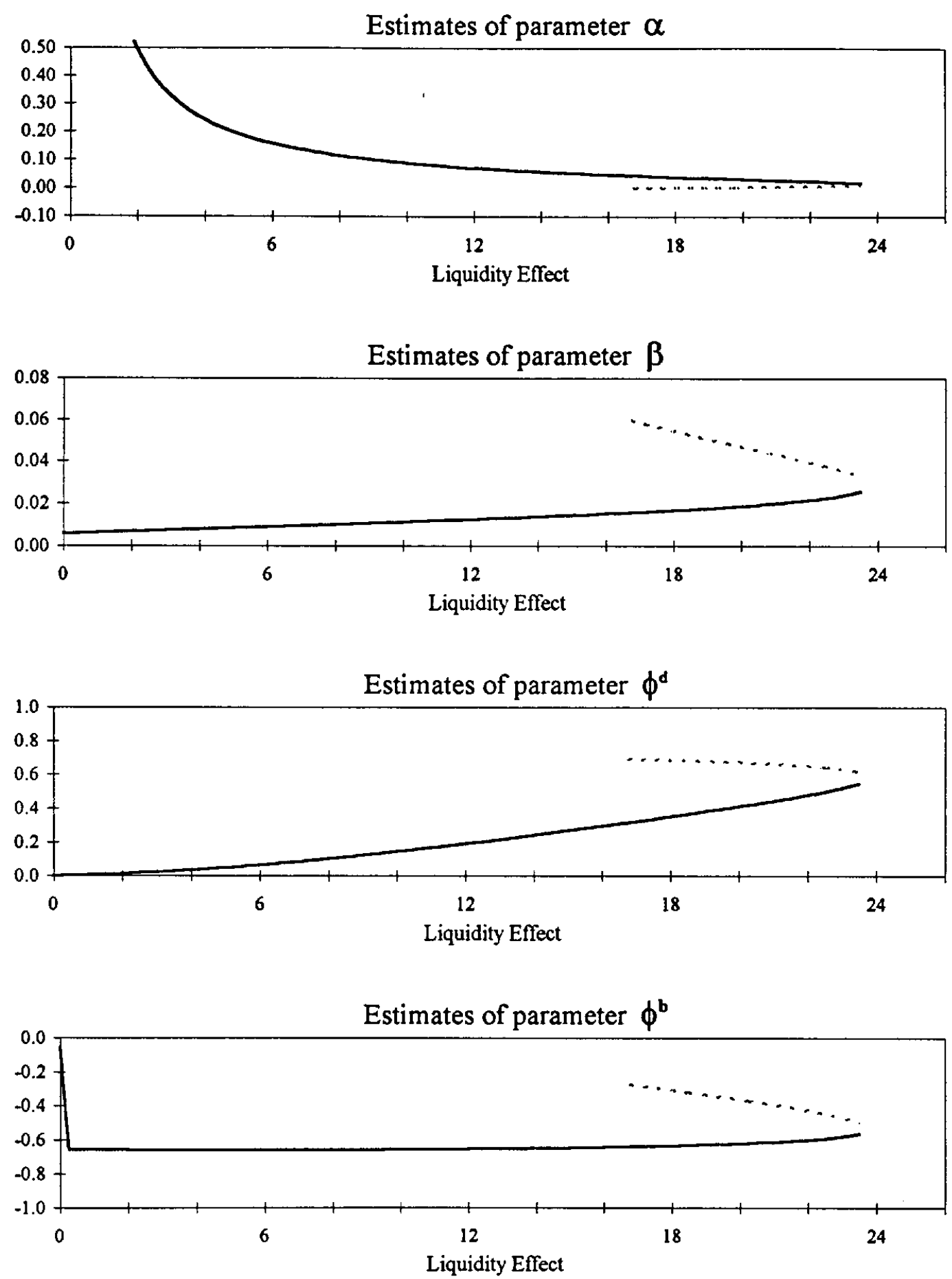

FIGURE VIII (b)

The Space of Admissible Structural Parameters (1982:10 - 1996:12) (partial-sample residuals) 